\title{
Insight into the Deep Eutectic Solvent Pretreatment of Oil Palm Empty Fruit Bunches: Effects of Temperature, Empty Fruit Bunch to Solvent Ratio, and Time
}

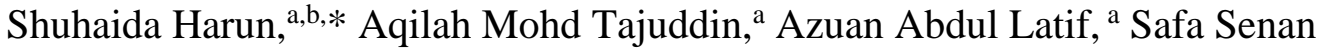 \\ Mahmod, a,b Mohd Shaiful Sajab, ${ }^{\text {a,b }}$ Masturah Markom, ${ }^{\text {a,b }}$ and Jamaliah Md Jahim ${ }^{\text {a,b }}$ \\ This work aimed to comprehensively examine the pretreatment efficiency \\ of oil palm empty fruit bunches (EFB) using two different types of deep \\ eutectic solvent (DES) mixtures, i.e., choline chloride/imidazole (DES-I) \\ and choline chloride/glycerol (DES-G) in terms of pretreated EFB \\ structural composition and enzymatic hydrolysis. The influence of the \\ pretreatment temperature $\left(55^{\circ} \mathrm{C}, 90^{\circ} \mathrm{C}, 125^{\circ} \mathrm{C}, 160^{\circ} \mathrm{C}\right.$, and $\left.195^{\circ} \mathrm{C}\right)$, \\ EFB to solvent ratio $(1: 5,1: 10,1: 15$, and $1: 20)$, and pretreatment time (2 \\ $\mathrm{h}, 4 \mathrm{~h}$, and $6 \mathrm{~h}$ ) on the performance of pretreated EFB and the generated \\ black liquor was examined. The optimal conditions for EFB pretreatment \\ were $160^{\circ} \mathrm{C}, 1: 5$ ratio, and $2 \mathrm{~h}$ using DES-I solvent, and $160^{\circ} \mathrm{C}, 1: 10$ ratio \\ and $4 \mathrm{~h}$ using DES-G solvent. The structural carbohydrates of empty fruit \\ bunch pretreated with DES-I, DES-I EFB1 and DES-G, DES-G EFB2 \\ increased to $66.1 \%$, and $64.6 \%$, respectively. The enzymatic hydrolysis of \\ DES-I EFB1 resulted in higher glucan conversion (92.4\%) compared to \\ DES-G EFB2, indicating that DES-I solvent was more efficient than DES- \\ $G$ for EFB pretreatment. X-ray diffraction, Fourier transform infrared \\ spectroscopy, and variable-pressure scanning electron microscopy \\ confirmed the removal of lignin and hemicelluloses from EFB during \\ pretreatment and enzymatic hydrolysis.
}

Keywords: Empty fruit bunch; Deep eutectic solvents; Dissolution; Pretreated EFB; Enzymatic hydrolysis; Glucan conversion

Contact information: a: Department of Chemical and Process Engineering, Faculty of Engineering and Built Environment, Universiti Kebangsaan Malaysia, Bangi, Selangor 43600 Malaysia; $b$ : Research Center for Sustainable Process Technology (CESPRO) Faculty of Engineering and Built Environment, Universiti Kebangsaan Malaysia, Bangi, Selangor 43600 Malaysia;

* Corresponding author: harun.shuhaida@ukm.edu.my

\section{INTRODUCTION}

Malaysia is the second largest crude palm oil producer in the world, after Indonesia, in which palm oil has become the single-largest commodity crop earner to Malaysia. The large-scale production of crude palm oil has consequently generated a large amount of palm-based by-products. It is reported that the palm oil processing only utilizes $10 \%$ of a palm oil tree for conversion into palm oil products, while the remaining $90 \%$ of the tree is converted into biomass residue, which is still underutilized (Hafyan et al. 2020). The solid waste produced from palm oil processing include empty fruit bunches (EFB), palm oil trunk (OPT), palm oil frond (OPF), and mesocarp fiber. The Malaysia Biomass Industries Confederation (MBIC) reported that there was approximately 19.5 million tons of EFB generated in 2015 (MBIC 2016). The abundant amount of EFB, if not managed properly, can eventually cause environmental problems, despite being a resource with high value 
applications. Hence, there is a need to convert EFB to value-added chemical feedstock that can benefit the palm oil industry.

The EFB consist of three primary components: cellulose (37\% to $59.7 \%)$, hemicellulose (16\% to 28\%), and lignin (10\% to 31\%) (Safri et al. 2017; Aini et al. 2018). Although EFB is regarded as a high-potential feedstock, it is still utilized for low value biomass-based products, e.g., fibers, compost, fuel, and fuel pellets. The complex and recalcitrant structure of the EFB posed by the intertwined carbohydrate-lignin structure has become the major hurdle for high value applications, signifying the need of a pretreatment as a key upstream process prior to high value applications such as biomass-derived fuels and chemicals (Lee et al. 2014; Hassan and Mutelet 2017; Tan et al. 2018). The pretreatment alters and opens up the EFB cell wall structure via hydrolyzing the hemicelluloses, degrading the lignin matrix, reducing the cellulose crystallinity, and finally making the cellulose more accessible to enzymes or acid during the hydrolysis process for producing fermentable sugars, which improves the carbohydrate conversion (Abdul et al. 2016).

Several types of pretreatments have been employed to pretreat EFB including chemical pretreatment, mechanical pretreatment, and biological pretreatment. Although chemical pretreatment using acid or alkali is the most common technique used to pretreat $\mathrm{EFB}$, it also has some drawbacks. The acid pretreatment is known to be less effective in removing lignin and results in lower sugar yield due to carbohydrate degradation into the enzyme-inhibiting byproducts, e.g., furfural, 5-hydroxymethylfurfural (HMF), formic acid, and levulinic acid (Cara et al. 2007; Jeong et al. 2012). Alkaline pretreatment causes the loss of hemicelluloses, and the formation of inhibitors under severe conditions. It also causes the formation of salts upon neutralization of the pretreated biomass, which may present challenges with its disposal during product purification (Prado et al. 2012)

Due to the environmental awareness, there is an increasing interest in utilizing ionic liquid (IL) as the pretreatment solvent. Ionic liquid fits the criteria of a green solvent, e.g., non-volatility and negligible vapor pressures (Wilkes 2002). However, it has the following disadvantages: a high cost, complex preparation of the solvent, low moisture tolerance, and toxic character (Degam 2017). The discovery of deep eutectic solvent (DES) may substitute for the role of IL due to its similar physico-chemical properties, and also has additional advantages, e.g., lower cost, easy synthesis, renewability, recyclability, high purity, low toxicity, non-flammability properties, and the fact that it is a biodegradable solvent (Zhang et al. 2012; Thi and Lee 2019). A DES is an eutectic liquid mixture of two or three components, which has the ability to establish a hydrogen bond interaction between the hydrogen bond donor (HBD) and the hydrogen bond acceptor (HBA) (Kalhor and Ghandi 2019). Majová et al. (2017) discussed the recovery of DES after pretreatment of biomass for further use, by subsequent evaporation of anti-solvent or simple freeze-drying of the washed solutions. Recently, DESs have been proposed as worthy alternatives for lignocellulose biomass dissolution (Zhao et al. 2013; Xia et al. 2014). Moreover, Lehmann et al. (2014) reported that DESs are good solvents for enzyme activity.

Recent work on EFB pretreatment using DES has been demonstrated by several researchers, who mostly reported on the efficient pretreatment using Type III DESs, i.e., choline chloride-lactic acid (Tan et al. 2018; Thi and Lee 2019; Sai and Lee 2019; Quek et al. 2020). Tan et al. (2018) used six different DESs, varying from acidic to basic in nature, and reported the combination of choline chloride-lactic acid produced the best result by achieving $100 \%$ hemicellulose extraction and $88 \%$ delignification compared to raw EFB.

Thi and Lee (2019) compared three combination of Type III DES using choline 
chloride, choline chloride-lactic acid (ChCl-LA), choline chloride-urea (ChCl-U), and choline chloride-glycerol ( $\mathrm{ChCl}-\mathrm{G})$ to pretreat EFB at a temperature of $120^{\circ} \mathrm{C}$ for $3 \mathrm{~h}$, with a solid to liquid ratio of 1:10 (w/v). Thi and Lee (2019) concluded that the pretreatment using acidic ChCl-LA was the best, which produced the highest reducing sugars yield (20.7\%). Sai and Lee (2019) further optimized the conditions of EFB pretreatment using $\mathrm{ChCl-LA}$ at a temperature of $100{ }^{\circ} \mathrm{C}$ for $1 \mathrm{~h}$ with a solid to solvent ratio of $1: 10(\mathrm{w} / \mathrm{v})$ and managed to achieve a maximum reducing sugars yield of $51.1 \%$ higher than dilute acid, alkaline, and organosolv pretreatments, which indicated the efficiency of DES pretreatment. Quek et al. (2020) demonstrated the delignification of EFB using the ultrasound-assisted $\mathrm{ChCl}$-LA pretreatment for $30 \mathrm{~min}$ at a temperature of $50{ }^{\circ} \mathrm{C}$ in a sonication bath that resulted in the reduction of total lignin content in the EFB from $31.6 \%$ to $18.8 \%$.

Imidazole, another green solvent in the amine group, can be used as a HBD in Type III DES to create a novel and sustainable approach in LCB pretreatment. It is an amphoteric molecule with base-dominating characteristics and previously has been used to pretreat corncob and wheat straw (Procentese et al. 2015; Morais et al. 2015). Procentese et al. (2015) used three different DES systems with choline chloride as the HBA and varied the HBD. They reported the pretreatment using choline chloride-imidazole conducted at a temperature of $115^{\circ} \mathrm{C}, 15 \mathrm{~h}$, and a solid to liquid ratio of $1: 16(\mathrm{w} / \mathrm{v})$ produced a glucose and xylose yields of $94 \%$ and $84 \%$, respectively, after enzymatic hydrolysis. The DES systems used were able to remove lignin, increase the biomass crystallinity, and reduce the cellulose crystallinity depending on the chosen DES. Morais et al. (2015) also reported the use of imidazole as a novel solvent for wheat straw fractionation and delignification to produce cellulose- and hemicellulose-rich fractions and depolymerized lignin. The highest recovery of cellulose-rich material was obtained at a temperature of $170{ }^{\circ} \mathrm{C}$ for $2 \mathrm{~h}$, achieving a $62.4 \%$ cellulose composition in the pretreated wheat straw compared to the $38.8 \%$ cellulose composition in native wheat straw. The enzymatic hydrolysis of imidazole-pretreated wheat straw resulted in a $99.3 \%$ glucan to glucose yield and extensive delignification (up to 92\%) for the cellulose-rich material.

Thus far, the DES mixture combination of choline chloride-imidazole has not been fully investigated in terms of EFB pretreatment. Although Tajudin et al. (2019) reported on the use of a choline chloride-imidazole mixture for pretreating different native EFB, there has been no comprehensive study on the effect of different pretreatment conditions, i.e., temperature, biomass to solvent ratio, and time, on the performance of pretreated EFB and the DES liquor residues after the pretreatment. Thus, the aim of this study was to further explore the efficiency of the EFB pretreatment using two different Type III DES mixtures, i.e., choline chloride-imidazole (DES-I) and choline chloride-glycerol (DES-G) based on the pretreated EFB structural composition and enzymatic hydrolysis. Hence, the work was intended to initially evaluate the effect of the pretreatment conditions using DESI and DES-G on the performance of pretreated EFB in the following ways: (1) EFB dissolution and chemical composition; (2) glucan conversion during enzymatic hydrolysis; and (3) the inhibitors in the DES liquor, which would be used to determine the optimal pretreatment conditions for EFB using DES-I and DES-G mixtures. The efficiency of the EFB pretreatment at optimal DES-I and DES-G conditions were determined based on the enzymatic hydrolysis and structural characterization of the pretreated EFB. To the best of the authors' knowledge, this is a pioneer comprehensive work that reports the usage of a choline chloride-imidazole eutectic mixture as a pretreatment agent during the pretreatment of EFB. 


\section{EXPERIMENTAL}

\section{Empty Fruit Bunch (EFB) Collection and Sample Preparation}

The native empty fruit bunch (EFB) sample used in this study was collected from the Sungai Siput Palm Oil Mill in Sungai Siput, Perak, Malaysia. The native EFB was dried under sunlight until the moisture content was less than 10\% (dry weight basis of the EFB). A moisture analyzer (IR-35, Denver Instrument, Arvada, CO) was used to measure the moisture content of the EFB samples. Then, the dried native EFB samples were ground using a universal cutting mill (PULVERISETTE 19, FRITSCH Universal, Idar-Oberstein, Germany), and sieved with a $2 \mathrm{~mm}$ sieve. The ground milled EFB samples were kept in a sealed plastic bag and stored in a $4{ }^{\circ} \mathrm{C}$ cold room until further use. The chemical composition of the native EFB samples was determined according to the National Renewable Energy Laboratory standard protocols as described in later section (Sluiter $e t$ al. 2012).

\section{Chemicals}

The analytical grade chemicals used for the DES-I and DES-G pretreatment were choline chloride, (+98\%), glycerol (+99\%), and imidazole (99\%), sourced from Alfa Aesar (Haverhill, MA). The analytical grade chemicals used for the analysis including the chemical composition, sugar, and inhibitor determination analyses were $\mathrm{D}(+)$-glucose, $\mathrm{D}(+)$-xylose, $\mathrm{L}(+)$-arabinose, sulphuric acid (95\% to 99\%), 5-Hydroxymethyl-2furaldehyde (99\%), acetic acid, furfural, $p$-coumaric acid, and ferulic acid sourced from Sigma-Aldrich (St. Louis, MO). The tri-sodium citrate dihydrate and citric acid monohydrate used for buffer preparation were sourced from Thermo Fisher Scientific (Waltham, MA). All these chemicals were purchased from Scienfield Expertise PLT (Selangor, Malaysia).

\section{Commercial Enzymes}

Two commercial enzyme cocktail mixtures were used in this study, i.e., Cellic ${ }^{\circledR}$ CTec2 (cellulase) and Cellic ${ }^{\circledR} \mathrm{HTec} 2$ (hemicellulase), which were purchased from Novozymes A/S (Bagsvaerd, Denmark). The Cellic ${ }^{\circledR}$ CTec2 contained a cocktail mixture of exo-1,4- $\beta$-glucanases (cellobiohydrolases), endo-1,4- $\beta$-glucanases, $\beta$-glucosidases and xylanase, and the Cellic ${ }^{\circledR}$ HTec2 mainly consisted of endo-1,4- $\beta$-xylanases. The respective enzyme activity for Cellic ${ }^{\circledR}$ CTec2 was $142 \mathrm{FPU} / \mathrm{mL} \pm 2.97 \mathrm{FPU} / \mathrm{mL}$ (with a protein concentration of $279.32 \mathrm{mg} / \mathrm{mL} \pm 1.10 \mathrm{mg} / \mathrm{mL}$ ).

\section{Synthesis of the Deep Eutectic Solvent (DES) Mixture}

Two different DESs were prepared using a mixture of choline chloride and imidazole at a molar ratio of 3:7, which was identified as the DES-I mixture, and choline chloride and glycerol at a molar ratio of 1:2, which was identified as the DES-G mixture. The respective DES synthesis, conducted in a $2 \mathrm{~L}$ glass beaker and covered with aluminum foil, was heated to a temperature of $100{ }^{\circ} \mathrm{C}$ and stirred at $500 \mathrm{rpm}$ for $2 \mathrm{~h}$ to $4 \mathrm{~h}$ at atmospheric pressure until it formed a homogeneous liquid. The DES mixtures were left to cool down to room temperature and then stored in sealed laboratory glass bottles. 


\section{Effect of Different Pretreatment Conditions and the Determination of Optimal Conditions}

The two eutectic mixtures synthesized in the previous section (DES-I and DES-G) were used as the solvents in the EFB pretreatment. First, $10 \mathrm{~g}$ of dried empty fruit bunches (EFB) was added into individual 2 L flasks containing the respective DES-I and DES-G solvents at different EFB to solvent ratios (1:5, 1:10, 1:15, and 1:20) and soaked at different temperatures $\left(55^{\circ} \mathrm{C}, 90^{\circ} \mathrm{C}, 125^{\circ} \mathrm{C}, 160^{\circ} \mathrm{C}\right.$, and $\left.195^{\circ} \mathrm{C}\right)$ for various amounts of time $(2 \mathrm{~h}$, $4 \mathrm{~h}$, and $6 \mathrm{~h}$ ). The pretreatment process was conducted on a hot plate at atmospheric pressure and stirred constantly at $500 \mathrm{rpm}$. Each bottle was sealed with cotton wool and aluminum foil to prevent vaporization of the sample during the pretreatment process. The pretreated EFB and DES liquor residues were separated via vacuum filtration and centrifugation after pretreatment. Finally, the pretreated EFB samples were dried overnight in an oven at a temperature of $40{ }^{\circ} \mathrm{C}$, then were stored in a cold room at a temperature of 4 ${ }^{\circ} \mathrm{C}$ until needed for further use and analysis. The performance of the pretreated EFB at different temperatures, ratios, and times were analyzed in terms of the EFB dissolution (\%), EFB chemical composition, and the glucan conversion during the $1 \%$ enzymatic hydrolysis. Additionally, the DES liquor residues were characterized to determine the presence of common inhibitors in the pretreatment. The optimal EFB pretreatment conditions for the respective DES-I and DES-G mixtures were determined using the onefactor-at-a-time method based on the EFB dissolution (\%), EFB chemical composition, and the glucan conversion during the $1 \%$ enzymatic hydrolysis.

\section{Empty Fruit Bunch (EFB) Dissolution during Deep Eutectic Solvent (DES) Pretreatment}

The EFB dissolution indicated the amount of solids loss to the solvent during the DES pretreatment and was determined based on the reduction in the dried mass recovered after the respective DES pretreatment, as shown in Eq. 1,

$$
\text { EFB Dissolution }(\%)=\left(1-\frac{m_{E F B, \text { after }}}{m_{E F B, \text { before }}}\right) \times 100 \%
$$

where $m_{E F B, b e f o r e}$ and $m_{E F B}$,after are the dried weight basis of the EFB mass (dwb) before and after the DES-I and DES-G pretreatment, respectively.

\section{Compositional Analysis of Native Empty Fruit Bunches (EFB) and the EFB Pretreated With Choline Chloride-Imidazole (DES-I) and Choline Chloride- Glycerol (DES-G)}

The chemical composition analysis was performed on the native EFB and the DES pretreated EFB using the laboratory analysis protocol (LAP) developed by the National Renewable Energy Laboratory (NREL) (Sluiter et al. 2012). All samples ( $n=3$ for each type of sample) were extracted with distilled water and 95\% ethanol using an accelerated solvent extractor (Dionex ASE 350, Thermo Scientific, Sunnyvale, CA) for the extractive removal before quantifying the structural carbohydrates and lignin during the acid hydrolysis step. The compositions of the EFB samples were characterized based on the structural carbohydrates, i.e., glucan, xylan, and arabinan, and lignin. 


\section{Enzymatic Hydrolysis of Choline Chloride-Imidazole (DES-I) and Choline Chloride-Glycerol (DES-G) Pretreated Empty Fruit Bunches (EFB)}

The enzymatic hydrolysis of native EFB, DES-I, and DES-G pretreated EFB, as well as EFB pretreated under optimal conditions for DES-I and DES-G (DES-I EFB1 and DES-G EFB2), were performed at a $1 \%$ glucan loading (w/v) in a $15 \mathrm{~mL}$ reaction volume (using $20 \mathrm{~mL}$ scintillation vials) in an incubated shaker (Infors HT Ecotron Incubator, Surrey, UK). The hydrolysis samples were buffered using a $1 \mathrm{M}$ citrate buffer (with a $\mathrm{pH}$ of 4.8) and loaded with Cellic CTec 2 cellulase at $15 \mathrm{FPU} / \mathrm{g}$ of glucan and combined with Cellic HTec2 hemicellulase at a ratio of 1:1 (v/v). All samples were incubated at a temperature of $50{ }^{\circ} \mathrm{C}, 150 \mathrm{rpm}$, and a $\mathrm{pH}$ of 4.8 for $72 \mathrm{~h}$. Upon completion, the hydrolysis samples were placed in capped tubes and heat-treated for $15 \mathrm{~min}$ at a temperature of 100 ${ }^{\circ} \mathrm{C}$ to denature the enzymes and terminate the hydrolysis reaction. All samples were centrifuged at $7000 \mathrm{rpm}$ for $10 \mathrm{~min}$ and then filtered through $0.22 \mu \mathrm{m}$ Whatman membrane syringe filters prior to high performance liquid chromatography (HPLC) carbohydrate analysis.

\section{High Performance Liquid Chromatography (HPLC) for Carbohydrate Quantification}

All carbohydrate monomers, i.e., glucose, xylose, and arabinose, were analyzed using high performance liquid chromatography. The HPLC system consists of a Dionex Ultimate 3000 HPLC (Thermo Fisher Scientific, Waltham, MA) equipped with a refractive index detector (ERC RefractoMax 520, Riemerling, Germany). A Rezek-RPM monosaccharide column (Phenomenex, Torrance, CA) with a de-ashing guard cartridge (Phenomenex, Torrance, CA) was used for monomeric sugar concentration analysis in water extractive samples for compositional analysis. Degassed HPLC grade water was used as the mobile phase at a flow rate of $0.6 \mathrm{~mL} / \mathrm{min}$ at a column temperature of $40{ }^{\circ} \mathrm{C}$. An additional Rezek-ROA monosaccharide column (Phenomenex, Torrance, CA) was used to quantify the sugar concentration of the acid hydrolysis samples. Sulfuric acid $\left(\mathrm{H}_{2} \mathrm{SO}_{4}\right)(5$ $\mathrm{mM}$ ) was used as the mobile phase at $0.6 \mathrm{~mL} / \mathrm{min}$ at a column temperature of $60{ }^{\circ} \mathrm{C}$. The HPLC sample injection volume was $20 \mu \mathrm{L}$. The standard calibration curves at different concentrations of individual and mixed sugars, i.e., glucose, xylose, arabinose, sucrose, fructose, and mannose, and sample quantifications were generated using Chromeleon chromatography data system (CDS) software (Ultimate 3000, Thermo Fisher Scientific, Waltham, MA).

\section{Carbohydrate Conversion}

The carbohydrate conversion of the native and pretreated EFB during enzymatic hydrolysis were reported in terms of glucan and xylan conversions and calculated using the actual monomeric and oligomeric sugars produced during the hydrolysis over the available theoretical sugar in the EFB samples, as shown in Eq. 2,

$$
\text { Carbohydrate Conversion }(\%)=\frac{C_{\text {Mono }}+C_{\text {Oligo }}}{T S C} \times V
$$

where $C_{M o n o}$ and $C_{\text {oligo }}$ are the monomeric and oligomeric sugar concentrations $(\mathrm{g} / \mathrm{L})$, respectively, $V$ is the volume of enzymatic hydrolysis reaction (L), and TSC is the theoretical sugar content in the EFB at the specified glucan loading (g). The glucan and xylan conversions were determined using the respective monomeric and oligomeric C6 and C5 sugars. 


\section{Characterization of Native Empty Fruit Bunches (EFB) and Choline Chloride-Imidazole (DES-I) and Choline Chloride-Glycerol (DES-G) Pretreated (EFB) at Optimal Pretreatment Conditions}

$X$-ray diffraction $(X R D)$ analysis for the crystallinity index measurement

The oven-dried $2 \mathrm{~mm}$ native EFB and DES pretreated EFB samples at optimal conditions for the DES-I and DES-G pretreatments (identified as DES-I EFB1 and DES-G EFB2), and the unhydrolyzed samples of DES-I EFB1 and DES-G EFB2 after hydrolysis were prepared for X-ray diffraction (XRD) scanning. Commercial high purity microcrystalline cellulose (Avicel® PH-101, CAS: 9004-34-6, Product Number: 11363) and lignin (Lignin, alkali, CAS: 8068-05-1, Product Number: 471003) were used as the control for comparison purposes.

The respective sample was spread evenly on the specimen disc, followed by crystallinity measurement using an Advance XRD device (Bruker AXS Inc., Fitchburg, WI) with $\mathrm{Cu} \mathrm{k \alpha 1}$ radiation source at a wavelength of $1.5406 \AA$ from a generator operating at $40 \mathrm{kV}$ and $40 \mathrm{~mA}$. All samples were analyzed at a speed of $0.25 \%$ at the range of $2 \theta$ from $20^{\circ}$ to $80^{\circ}$. The XRD data were used to determine the crystallinity index (CrI) by the ratio of the scattering maximum intensity of the crystalline peak ( $\left.I_{002}\right)$ and the scattering minimum intensity of the amorphous peak $\left(I_{\mathrm{am}}\right)$, according to Eq. 3,

$$
\mathrm{CrI}=\frac{I_{002}-I_{a m}}{I_{002}} \times 100 \%
$$

where $I_{002}$ is the intensity of the peak at the 002 lattice diffraction (crystalline region, $2 \theta=$ $22.6^{\circ}$ ) and $I_{\mathrm{am}}$ is the intensity of the peak at the 001 amorphous phase (amorphous region, $\left.2 \theta=18^{\circ}\right)($ Oh et al. 2005).

Fourier transform infrared (FTIR) analysis for functional group determination

The Fourier transform infrared (FTIR) analysis on all the oven-dried native EFB, DES-I EFB1, DES-G EFB2, UH DES-I EFB1 and UH DES-G EFB2 samples were performed using a Nocilet 67000 FTIR spectrophotometer (Thermo Fisher Scientific, Waltham, MA) based on the method of attenuated total reflectance (ATR). All samples were scanned with the range from 4000 to $400 \mathrm{~cm}^{-1}$ at a wavelength resolution of $2 \mathrm{~cm}^{-1}$ and recorded in transmission mode. The FTIR analysis was also used to determine the ratio of the lateral order index (LOI), total crystallinity index (TCI), and hydrogen-bond intensity (HBI). The LOI was determined by the wavelength ratio of 1437 to $899 \mathrm{~cm}^{-1}$, the TCI was determined by the wavelength ratio of 1378 to $2900 \mathrm{~cm}^{-1}$, and the HBI was ascertained by the wavelength ratio of 308 to $1330 \mathrm{~cm}^{-1}$ (Oh et al. 2005; Shah et al. 2020).

Variable pressure scanning electron microscopy (VPSEM) analysis for empty fruit bunch (EFB) morphological changes

Morphological analysis of the native EFB, DES-I EFB1, DES-G EFB2, UH DESI EFB1, and UH DES-G EFB2 samples were conducted using variable pressure scanning electron microscopy (VPSEM) (EVO MA10 CARL ZEISS, Cambridge, UK). All samples were freeze-dried before the scanning analysis. The samples were placed on aluminum stubs and coated with gold using a sputter coater system (Q150R S, Quorum Technologies, Lewes, UK). The magnification range was between $50 \times$ and $1000 \times$ for each sample. 


\section{RESULTS AND DISCUSSION}

\section{Chemical Composition of Native Untreated Empty Fruit Bunches (EFB)}

The primary structural components of EFB are made up of cellulose, hemicellulose, and lignin, where the cellulose and hemicellulose formed the structural carbohydrate (SC) in the biomass. The chemical composition of native untreated EFB was found to be consisting of $61.2 \% \pm 1.95 \%$ SCs and $22.3 \% \pm 0.8 \%$ lignin, where the SC was formed of $37.6 \% \pm 0.41 \%$ glucan, $22.6 \% \pm 0.2 \%$ xylan, and $0.9 \% \pm 1.32 \%$ arabinan. This composition result obtained was consistent and fell within the range of reported compositions for native EFB (Abdul et al. 2016).

\section{Effects of the Pretreatment Temperature}

Empty fruit bunch $(E F B)$ dissolution and chemical composition of deep eutectic solvent (DES) pretreated $E F B$

Figure 1a and Fig. 1b show the effects of the pretreatment temperature on the EFB dissolution and the chemical composition of the pretreated EFB after DES-I and DES-G pretreatment conducted at a EFB to solvent ratio of $1: 10$ for $4 \mathrm{~h}$ at a temperature range of 55 to $195^{\circ} \mathrm{C}$. Generally, the temperature influenced the DES-I and DES-G solvents during pretreating and dissolving the EFB into the liquid. The EFB mass dissolution in the solvent gradually increased for the EFB pretreated with DES-I (as shown in Fig. 1a) from 16.4\% to $45.7 \%$, and from $10.2 \%$ to $44.5 \%$ for the EFB pretreated with DES-G (as shown in Fig. 1b) when the temperature increased from 55 to $195^{\circ} \mathrm{C}$.

The increasing temperature has been reported to alter the ionic characteristics and the molecular polarity of the DES solvent, promoting the breakage of the intramolecular hydrogen bond network, and enhancing the solubility of the carbohydrates and lignin in the DES solvents (Chen et al. 2019). The dissolution of the solids into the liquid could also be affected by the decreasing viscosity of the DES solvent as the temperature increased (Degam 2017). Additionally, it can be observed that the EFB dissolution was slightly higher in DES-I compared to DES-G, which was likely due to the hydrogen bond basicity, which promoted better dissolution. During the pretreatment, it was observed that the $\mathrm{pH}$ of DES-I ranged from 8.59 to 8.19, while the $\mathrm{pH}$ of DES-G ranged from 6.41 to 6.28.

The increase in temperature also modified the chemical composition of the DES-I and DES-G pretreated EFB, since the amount of hemicelluloses (xylan and arabinan) and lignin retained in the pretreated EFB were reduced compared to native EFB. As the temperature was increased from 55 to $195{ }^{\circ} \mathrm{C}$, the hemicellulose fraction in the DES-I and DES-G pretreated EFB was reduced from $23.5 \%$ in the native EFB to $15.4 \% \pm 0.5 \%$ and $14.3 \% \pm 0.0 \%$, respectively, at a temperature of $195{ }^{\circ} \mathrm{C}$ (as shown in Fig. 1a and Fig. 1b). A similar trend was also observed for lignin, where the fraction in DES-I and DES-G pretreated EFB was reduced from $22.3 \%$ in the native EFB $12.8 \% \pm 0.6 \%$ and $13.6 \% \pm$ $0.5 \%$ respectively, at a temperature of $195{ }^{\circ} \mathrm{C}$ (as shown in Fig. 1a and Fig. 1b). A greater reduction in the lignin fraction was observed in the DES-I pretreated EFB, which was most likely due to the hydrogen bond basicity of the DES-I solvent compared to DES-G (Degam 2017; Hassan and Mutelet 2017; Horváth et al. 2017).

While the temperature had an inverse effect on the hemicellulose and lignin compositions, a different trend was observed in the structural glucan composition in both the DES-I and DES-G pretreated EFB. The glucan fractions in both pretreated EFB gradually increased as the temperature increased from 55 to $160{ }^{\circ} \mathrm{C}$ (as shown Fig. 1a and Fig. $1 \mathrm{~b})$ and reached the highest glucan composition $(45.1 \% \pm 0.4 \%$ and $48.9 \% \pm 0.8 \%$, 
with respect to DES-I and DES-G pretreated EFB) at a temperature of $160{ }^{\circ} \mathrm{C}$. This increasing trend in the cellulose fraction of the pretreated EFB was primarily due to the dissolution of the hemicellulose and lignin in the DES solvent. However, further increase of the temperature from 160 to $195{ }^{\circ} \mathrm{C}$ resulted in a sudden reduction of the glucan fraction from $45.1 \% \pm 0.4 \%$ to $37.8 \% \pm 0.2 \%$ in DES-1 pretreated EFB (as shown in Fig. 1a), with a $16.2 \%$ reduction, and from $48.9 \% \pm 0.8$ to $38.3 \% \pm 0.5 \%$ in DES-G pretreated EFB (as shown in Fig. 1b), with a $21.7 \%$ reduction. This reduction could be due to the further dissolution and degradation of the cellulose chain at high temperatures (Arumugam et al. 2020). Other studies have reported that at higher temperature ranges, certain IL are capable of dissolving cellulose molecules by breaking down the inter- and intra-molecular hydrogen bond networks between cellulose molecules and making a new IL-cellulose hydrogen bond network, which promotes cellulose dissolution. This also could be contributed by the high interaction energy, hydrogen bond formation, bond acidity, or basicity and polarity between the cellulose and the solvent (Brandt et al. 2013; Hassan and Mutelet 2017).

Glucan conversion of deep eutectic solvent (DES) pretreated empty fruit bunches (EFB)

Figure $1 \mathrm{a}$ and Fig. $1 \mathrm{~b}$ show the effect of the pretreatment temperature on the glucan conversion obtained during the $1 \%$ enzymatic hydrolysis of both DES-I and DES-G pretreated EFB. The result showed that the highest glucan conversion was attained when the temperature was at $160{ }^{\circ} \mathrm{C}(67.8 \%$ and $71.4 \%$ for DES-I and DES-G pretreated EFB, respectively). The pretreatment conditions (a temperature of $160{ }^{\circ} \mathrm{C}$, a 1:10 ratio, and $4 \mathrm{~h}$ ) that yielded the highest glucan fraction for both DES-I and DES-G pretreated EFB were the result of the solubilization of a majority of the hemicelluloses (27\% to 32\%) and lignin (34\% to $40 \%$ ) into the DES solvents. Glucan conversion was declined at further increase in temperature (at $195^{\circ} \mathrm{C}$ ), which resulted in the formation of inhibitors such as HMF and furfural in both DES-I and DES-G pretreated EFB samples, as shown in Fig. 1c and Fig. $1 d$.

\section{Inhibitors in the deep eutectic solvent (DES) black liquor}

Severe pretreatment conditions can possibly cause degradation of the glucans and hemicelluloses in the biomass, causing the formation of inhibitors, e.g., hydroxyl-methyl furfural (HMF), furfural, acetic acid (AA), etc., and the depolymerization of lignin releasing phenolic compounds, e.g., gallic acid, ferulic acid (FA), and $p$-coumaric acid (pCA), in the solvent turning it to black liquor (Jönsson et al. 2013; Mahmod et al. 2017; Bukhari et al. 2019). Figure 1c and Fig. 1d show the effects of the pretreatment temperature on the concentration of the inhibitors released from the EBF, with respects to the DES-I and DES-G solvents at a 1:10 solvent ratio and a $4 \mathrm{~h}$ pretreatment time.

The concentration of inhibitors increased as the temperature increased, which corresponded to greater EFB dissolution in the solvent at higher temperatures. The concentration of glucose, xylose, and AA gradually increased as the temperature increased; however, their concentrations were consistently lower in the DES-I black liquor compared to the DES- G black liquor throughout the temperature interval. The highest concentration of glucose, xylose, and AA in the DES-I black liquor were $266.5,125.3$, and $273.6 \mathrm{mg} / \mathrm{L}$ at a temperature of $195{ }^{\circ} \mathrm{C}$ (as shown in Fig. 1c) compared to 355.7, 205, and $709.5 \mathrm{mg} / \mathrm{L}$ in the DES-G black liquor at the same temperature (as shown in Fig. 1d). Furfural, HMF, FA, and pCA were observed to be selectively present in different liquors. While furfural steadily increased and dominated the DES-I black liquor with a highest concentration of 
$481.8 \mathrm{mg} / \mathrm{L}$ at a temperature of $195^{\circ} \mathrm{C}$, HMF was observed to dominate the DES-G black liquor with its abrupt increase in concentration from $579 \mathrm{mg} / \mathrm{L}$ at a temperature of $160{ }^{\circ} \mathrm{C}$ to $1276 \mathrm{mg} / \mathrm{L}$ at a temperature of $195^{\circ} \mathrm{C}$. Menegazzo et al. (2018) reported that under some pretreatment conditions using IL, the biomass could directly transform to HMF in a one step process. Ferulic acid was found to appear in both the DES-I and DES-G black liquors (as shown in Fig. 1c and Fig. 1d), while pCA was detected only in the DES-G black liquor (as shown in Fig. 1d). Previous work indicated that FA acts a "bridge" between the lignin via etherified bonding, and between the carbohydrates via esterified bonding in the lignin carbohydrate complex (LCC). Hence, FA can therefore be released either under acid or alkaline conditions through its acid labile etherified bonding or alkaline labile esterified bonding (Buranov and Mazza 2008; Koshijima and Watanabe 2013).

The pCA binds with lignin or carbohydrates primarily through esterified bonds, which are only labile under alkaline conditions (Linh et al. 2017; Li et al. 2019). The pH of the respective DES-I and DES-G solvents was recorded at 8.4 and 6.4, which explained why only FA was released in the acidic EFB pretreatment using the DES-G solvent. Linh et al. (2017) observed that FA was released considerably faster than pCA. Although pCA had a broad distribution throughout the lignin matrix, it tended to be densely located in the lignin fraction that is not easily solubilized via the alkaline pretreatment. Figure 1c indicates that the highest concentration of FA and pCA in the DES-I black liquor was 5.9 and $4.2 \mathrm{mg} / \mathrm{L}$, respectively, while the FA concentration in the DES-G black liquor was 9.1 $\mathrm{mg} / \mathrm{L}$ at a temperature of $195^{\circ} \mathrm{C}$. 

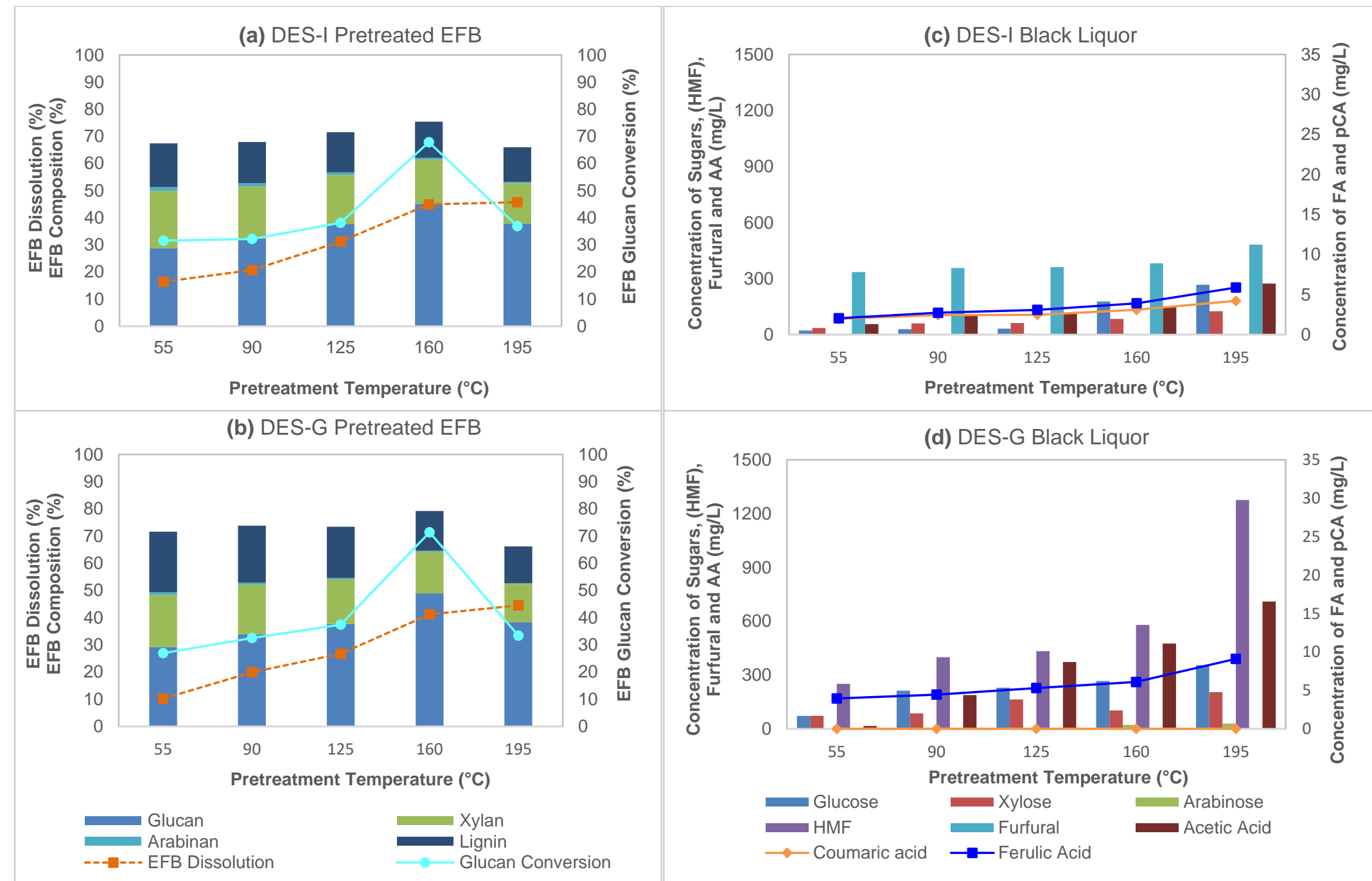

Fig. 1. Effect of the pretreatment temperature on (a) DES-I pretreated EFB, (b) DES-G pretreated EFB, (c) DES-I black liquor, and (d) DES-G black liquor at a EFB to solvent ratio of $1: 10$ and a treatment time of $4 \mathrm{~h}$ 


\section{Optimal temperature for subsequent choline chloride-imidazole (DES-I) and choline chloride-glycerol (DES-G) pretreatment}

The performance of the pretreated EFB in terms of the chemical composition and the glucan conversion showed that a temperature of $160{ }^{\circ} \mathrm{C}$ was the optimal pretreatment temperature for DES-I and DES-G to achieve the highest glucan composition and conversion of the DES-I and DES-G pretreated EFB. The temperature was applied to the subsequent DES-I and DES-G pretreatments to further determine the effect of the EFB to solvent ratio and pretreatment time.

\section{Effects of the Empty Fruit Bunch (EFB) to Solvent Ratio}

Empty fruit bunch (EFB) dissolution and chemical composition of deep eutectic solvent (DES) pretreated $E F B$

Figure $2 \mathrm{a}$ and Fig. $2 \mathrm{~b}$ show the effect of the EFB to solvent ratio on the EFB dissolution and chemical composition during the DES-I and DES-G pretreatment of EFB at a ratio of $1: 5$ to $1: 20$ at a temperature of $160{ }^{\circ} \mathrm{C}$ for $4 \mathrm{~h}$. The rate of EFB mass dissolution in the DES-I solvent gradually increased from $31.7 \%$ to $49.9 \%$ when the ratio increased from 1:5 to 1:15; the dissolution rate was maintained when the ratio was further increased to 1:20 (as shown in Fig. 2a). However, for the DES-G solvent, the EFB mass dissolution continuously increased from $25.9 \%$ to $48.8 \%$ when the ratio increased from 1:5 to 1:20 (as shown in Fig. 2b).

Technically, a ratio of solid to solvent should be kept high to facilitate greater throughput of material through a pretreatment process, thus yielding higher production rates. However, a higher solid to solvent ratio could also result in higher production cost. Hence, sufficient amount of solvent should be used to dissolve both lignin and hemicelluloses as well as to retain most of the crystalline cellulose in the remaining EFB solid. Figure 2a and Fig. 2b show the effect of the EFB to solvent ratio on the composition of the DES-I and DES-G pretreated EFB as it increased from 1:5 to 1:20. The hemicellulose (xylan and arabinan) fraction was drastically reduced from $23.5 \%$ in the native EFB to $16.4 \%$ and $15.7 \%$ in the respective DES-I and DES-G pretreated EFB at a ratio of 1 to 10 (as shown in Fig. 2a and Fig. 2b). However, for both DES pretreatments, a further increasing of the ratio resulted in an increase in the hemicellulose fraction.

When the ratio was increased from 1:5 to 1:20, the lignin composition fraction was observed to steadily reduce over the ratio interval, reaching its lowest composition of $11 \%$ $\pm 0.8 \%$ and $12.8 \% \pm 0.4 \%$ in the DES-I and DES-G pretreated EFB at a ratio of $1: 20$ (as shown in Fig. 2 a and Fig. 2b). This resulted in a lignin reduction of 50.6\% and $42.6 \%$ from the native EFB in comparison to DES-I and DES-G pretreated EFB, respectively. A higher lignin reduction was observed in the DES-I pretreated EFB, owing to the alkaline conditions of the solvent, which allowed the cleavage of the alkaline labile ester bonding in the lignin fraction.

The trend of the structural glucan composition in both the DES-I and DES-G pretreated EFB is interesting enough to be highlighted. The glucan composition in the DES-I pretreated EFB attained the highest composition $(48.4 \% \pm 0.4 \%)$ at the lowest ratio of 1:5. It is clearly shown that the lowest ratio, when coupled with the high pretreatment temperature at $160{ }^{\circ} \mathrm{C}$, caused the DES-I pretreated EFB to experience considerable removal of the hemicellulose (28\%) and lignin (40\%) fractions, which resulted in a higher composition of the glucan fraction (as shown in Fig. 2a). Further increasing of the ratio gradually reduced the glucan composition, which is most likely caused by the dissolution of some amorphous structure in the glucan fraction. Roy et al. (2020) reported that 
imidazole-based IL pretreatment significantly helps the removal of the cellulose portion of the biomass as well as cleaving the $\beta$-O-4 linkages.

However, the glucan fraction in the DES-G pretreated EFB increased when the ratio was increased to $1: 10$, with a glucan fraction of $48.9 \% \pm 0.8 \%$, but this fraction was subsequently reduced as the ratio was increased to 1 to 20 , which was likely caused by the amorphous region dissolution in the solvent.

Rahim et al. (2021) reported that the low viscosity of 1-(2-methoxyethyl)-3methylimidazolium chloride $(\mathrm{MOE}-\mathrm{MImCl})$ is a primary factor in improving the dissolution of bamboo in ILs, since it boosts the mass transfer of the solute, thus leading to a higher percentage of biomass dissolution. Thus, the DES viscosity can influence the biomass to solvent ratio during the pretreatment process. A low viscosity DES-I solvent required a low EFB to solvent ratio since it could easily diffuse into the biomass structure and boost the solute mass transfer. The experimental data indicated that at a temperature of $160{ }^{\circ} \mathrm{C}$, the DES-I solvent had a lower viscosity compared to DES-G, which is likely the reason for the low ratio required for the DES-I solvent.

Glucan conversion of deep eutectic solvent (DES) pretreated empty fruit bunches (EFB)

Figure $2 \mathrm{a}$ and Fig. $2 \mathrm{~b}$ show the effects of the EFB to solvent ratio on the glucan conversion during the $1 \%$ enzymatic hydrolysis of both the DES-I and DES-G pretreated EFB at a temperature of $160{ }^{\circ} \mathrm{C}$ and a treatment time of $4 \mathrm{~h}$. The hydrolysis of the DES-I pretreated EFB attained the highest glucan conversion (85.9\%) at a ratio of 1:5, while the hydrolysis of the DES-G pretreated EFB required a higher ratio (1:10) in order to attain its highest glucan conversion rate of $71.5 \%$. The composition of the DES-I and DES-G pretreated EFB at the respective ratios indicated the solubilized amount of hemicellulose and lignin were $27 \%$ and $40 \%$ in the DES-I liquor, respectively, and $32 \%$ and $34 \%$ in the DES-G liquor, respectively.

\section{Inhibitors in the black liquor of the deep eutectic solvent (DES) pretreatments}

Figure $2 \mathrm{c}$ and Fig. 2d show the effects of the EFB to solvent ratio on the concentration of the inhibitors released into the liquors during the DES-I and DES-G pretreatment of EFB at a temperature of $160{ }^{\circ} \mathrm{C}$ and a treatment time of $4 \mathrm{~h}$. The concentration of the inhibitors, particularly glucose, xylose, and AA, increased in the DESI liquor when the ratio increased, which was likely due to additional EFB dissolution into the solvent at higher ratios (as shown in Fig. 2c). However, the opposite trend was observed in the DES-G liquor (as shown in Fig. 2d). As the ratio increased, the concentration of glucose and xylose gradually decreased, but AA was observed to maintain a slow increase in concentration. Furfural dominated the DES-I black liquor with the highest concentration of $500 \mathrm{mg} / \mathrm{L}$ at a 1:20 ratio, while HMF dominated the DES-G black liquor with its concentration suddenly increasing from $487.9 \mathrm{mg} / \mathrm{L}$ at a ratio of $1: 15$ to $1426.1 \mathrm{mg} / \mathrm{L}$ at a ratio of 1:20.

The FA was found in both the DES-I and DES-G liquors (as shown in Fig. 2c and Fig. 2d) while pCA was only found in the DES-G liquor (as shown in Fig. 2d), as described in a previous section. The formation of these inhibitory products during pretreatments were below the inhibition ranges tested on the cell growth of microorganisms, e.g., Saccharomyces cerevisiae, at a range of $500 \mathrm{mg} / \mathrm{L}$ to $4000 \mathrm{mg} / \mathrm{L}$ of furfural, and Zymomonas mobilis, at a range of $960 \mathrm{mg} / \mathrm{L}$ to $2000 \mathrm{mg} / \mathrm{L}$ (Banerjee et al. 1981; Delgenes et al. 1996). 

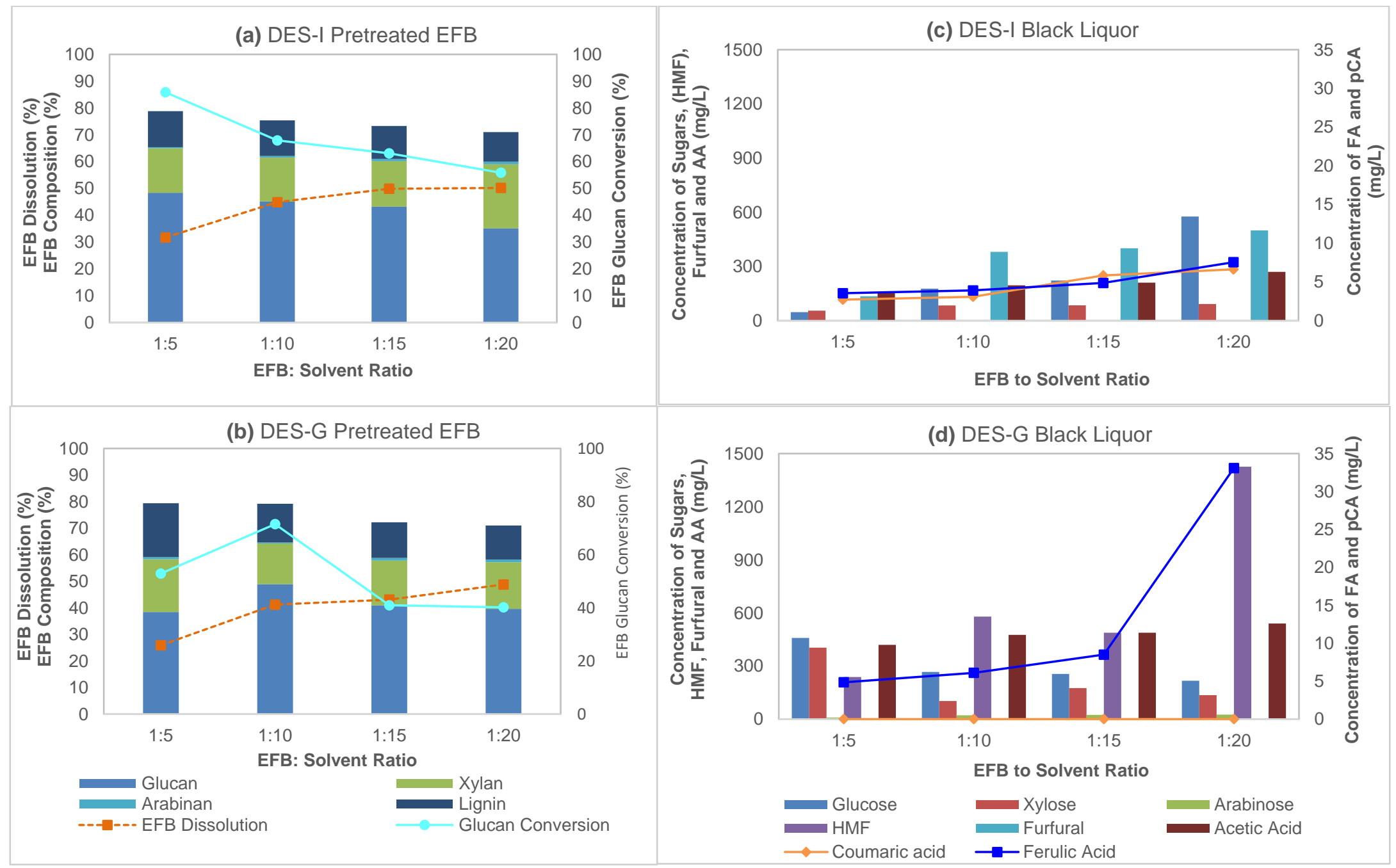

Fig. 2. Effect of the EFB to solvent ratio on (a) DES-I pretreated EFB, (b) DES-G pretreated EFB, (c) DES-I black liquor, and (d) DES-G black liquor at a temperature of $160^{\circ} \mathrm{C}$ and a treatment time of $4 \mathrm{~h}$ 
Optimal empty fruit bunch (EFB) to solvent ratio for subsequent choline chlorideimidazole (DES-I) and choline chloride-glycerol (DES-G) pretreatment

The EFB to solvent ratio also had a considerable effect on the chemical composition as well as the glucan conversion of the DES-I and DES-G pretreated EFB. Values of 1:5 and 1:10 were the optimal ratios for the DES-I and DES-G pretreatment to attain the highest glucan composition and conversion during the enzymatic hydrolysis. The optimal temperature of $160{ }^{\circ} \mathrm{C}$ and a ratio of 1:5 and 1:10 were applied in the subsequent DES-I and DES-G pretreatments to further determine the effect of the treatment time on the pretreated EFB.

\section{Effect of the Pretreatment Time}

Empty fruit bunch $(E F B)$ dissolution and chemical composition of deep eutectic solvent (DES) pretreated $E F B$

Figures $3 a, b$ show the effects of pretreatment time on the EFB dissolution and the chemical composition of the DES-I and DES-G pretreated EFB, which ranged from 2 to 6 $\mathrm{h}$, at $160{ }^{\circ} \mathrm{C}$. The EFB to solvent ratios were 1:5 for the DES-I pretreatment and 1:10 for the DES-G pretreatment. When the pretreatment time was increased from 2 to $6 \mathrm{~h}$, the EFB dissolution in the solvent gradually increased from $29.9 \%$ to $46.2 \%$ for DES-I pretreated EFB (Fig. 3a), and from $23.6 \%$ to $44.4 \%$ for the DES-G pretreated EFB (Fig. 3b).

Although increasing the pretreatment time caused an increase in the solid-liquid interaction that resulted in a higher removal of lignin (approximately $41 \%$ in the DES-I pretreated EFB), it also reduced the glucan composition from $51.9 \% \pm 0.2 \%$ at $2 \mathrm{~h}$ to $42.2 \%$ $\pm 0.5 \%$ at $6 \mathrm{~h}$, which caused the hemicellulose fraction to increase. The treatment time of $2 \mathrm{~h}$ was already sufficient to remove $37 \%$ of the lignin in the DES-I pretreated EFB. However, for the DES-G pretreated EFB, a longer time was required to remove a greater amount of lignin from the EFB, due to the higher viscosity of the DES-G solvent. When the EFB was pretreated with DES-G for $4 \mathrm{~h}, 34.5 \%$ of the lignin were removed from the biomass, which resulted in the highest glucan composition of $48.9 \% \pm 0.8 \%$, and a further increased in pretreatment time would only cause glucan solubilization.

Glucan conversion of deep eutectic solvent (DES) pretreated empty fruit bunches (EFB)

Figures $3 \mathrm{a}$ and $3 \mathrm{~b}$ also showed the effect of pretreatment time on glucan conversion during $1 \%$ enzymatic hydrolysis of the DES-I and DES-G pretreated EFB from 2 to $6 \mathrm{~h}$. The glucan conversion of the DES-I pretreated EFB reduced from $92.4 \%$ after $2 \mathrm{~h}$ to $69.2 \%$ after $6 \mathrm{~h}$ (Fig. 3a). For the DES-G pretreated EFB, the glucan conversion reached its highest conversion rate $(71.8 \%)$ when the EFB was pretreated for $4 \mathrm{~h}$, due to the highest glucan composition in the biomass (Fig. 3b). However, this conversion was much lower compared to the glucan conversion of the DES-I pretreated EFB with a $2 \mathrm{~h}$ pretreatment time.

\section{Inhibitors in the black liquor of the deep eutectic solvent (DES) pretreatments}

Figures $3 \mathrm{c}$ and $3 \mathrm{~d}$ show the effect of pretreatment time on inhibitor concentration in the DES-I and DES-G black liquors, with a pretreatment time ranging from 2 to $6 \mathrm{~h}$. The DES-I liquor yielded a low concentration of glucose, xylose, furfural, AA, FA, and pCA at 2 and $4 \mathrm{~h}$ pretreatment times, with the concentration of each inhibitor less than $150 \mathrm{mg} / \mathrm{L}$ (Fig. 3c). However, the concentration of all inhibitors was consistently higher in the DES$\mathrm{G}$ liquor, ranging from a pretreatment time of $2 \mathrm{~h}$ up to $6 \mathrm{~h}$, particularly glucose, xylose, AA, HMF, and FA (Fig. 3d). The higher concentration of inhibitors also could cause the lower glucan conversion during the hydrolysis of the DES-G pretreated EFB. 

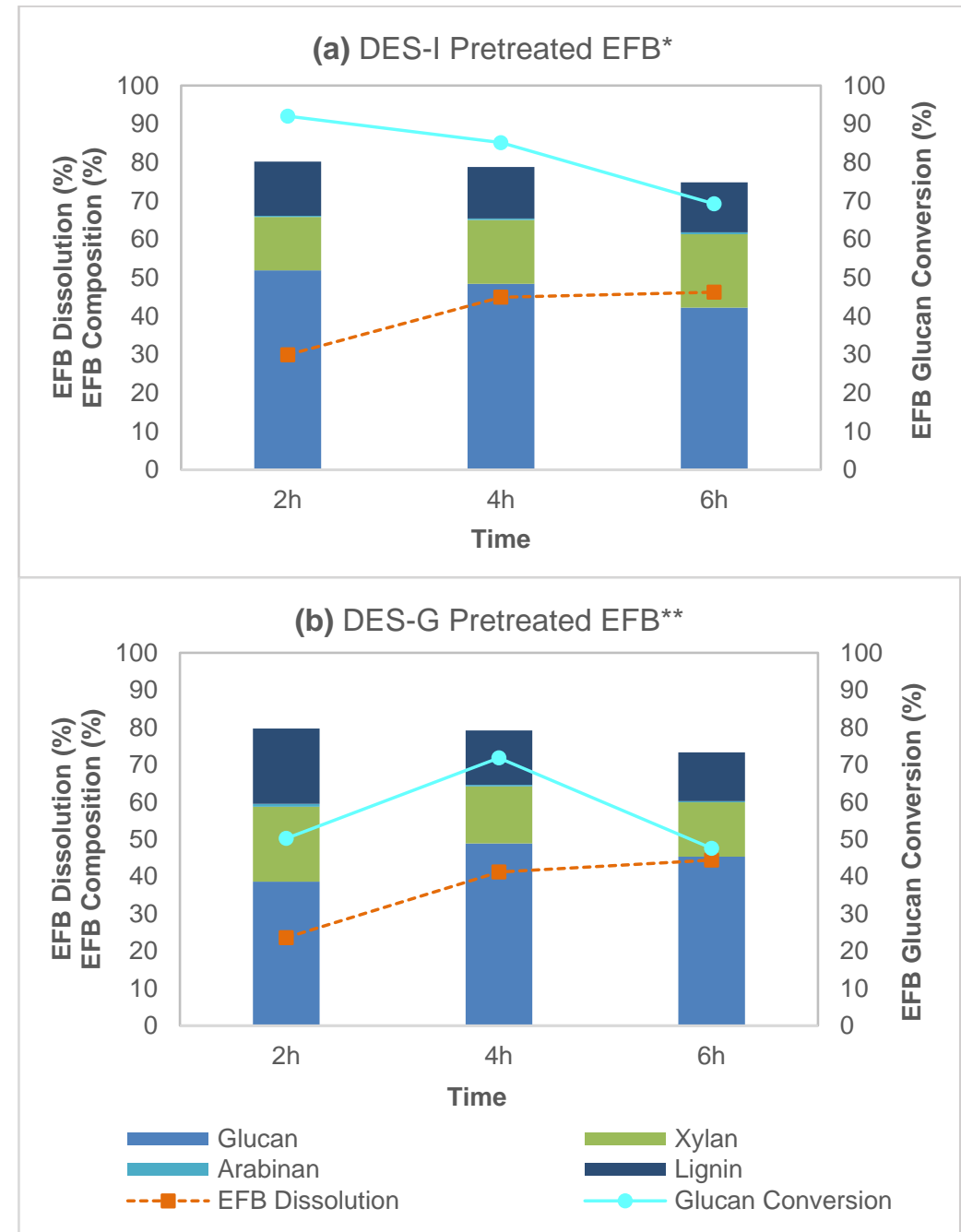
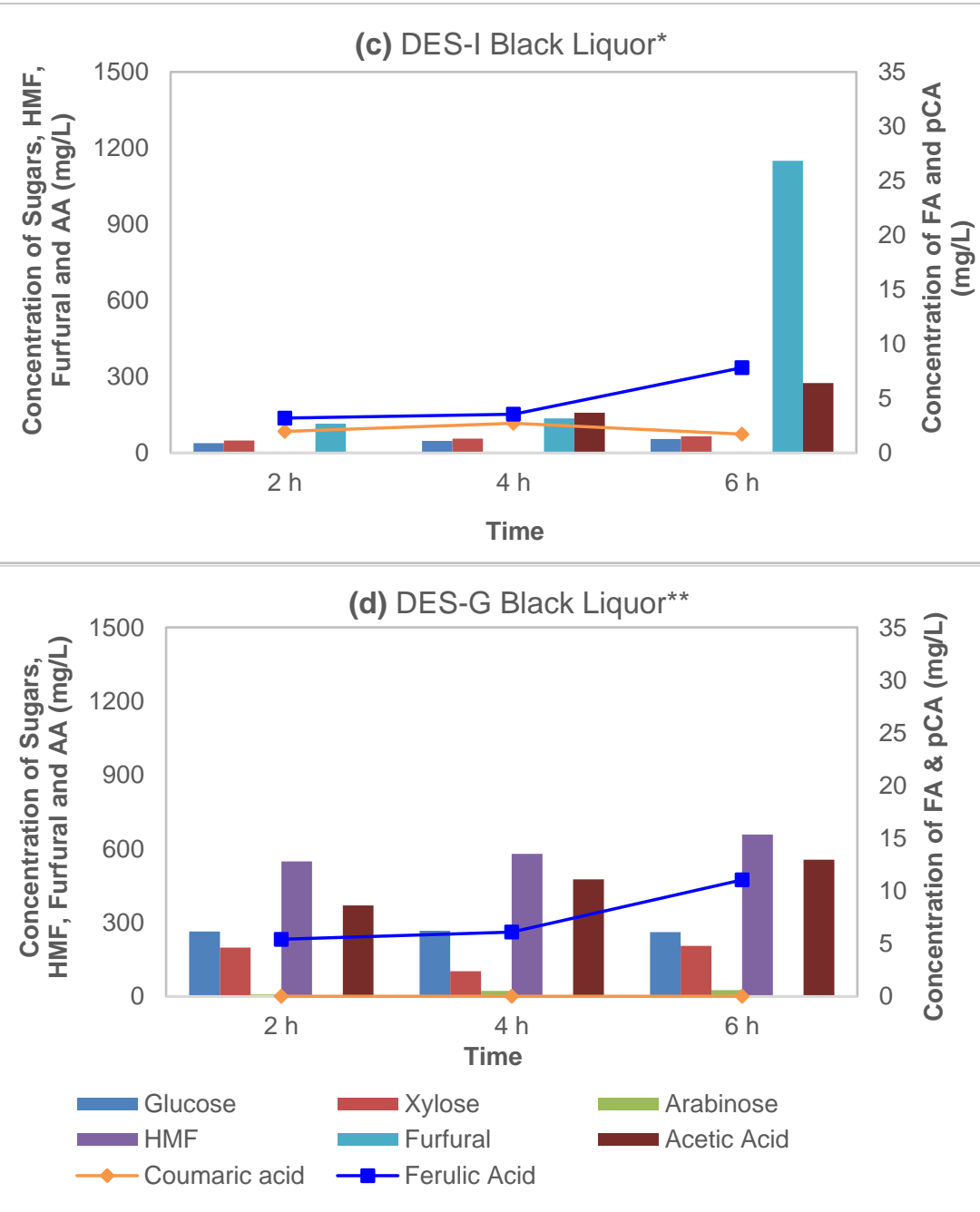

Fig. 3 Effect of the pretreatment time (a) DES-I pretreated EFB, (b) DES-G pretreated EFB, (c) DES-I black liquor, and (d) DES-G black liquor at a temperature of $160^{\circ} \mathrm{C}$ and a EFB to solvent ratio of 1 to 5 for DES-I and 1 to 10 for DES-G 
Optimal choline chloride-imidazole (DES-I) and choline chloride-glycerol (DES-G) pretreatment conditions for empty fruit bunches $(E F B)$

The results indicated that the optimal conditions for DES-I pretreatment were a temperature of $160{ }^{\circ} \mathrm{C}$, a EFB to solvent ratio of 1:5, and a pretreatment time of $2 \mathrm{~h}$. The optimal DES-G pretreatment conditions were a temperature of $160{ }^{\circ} \mathrm{C}$, a EFB to solvent ratio of 1:10, and a pretreatment time of $4 \mathrm{~h}$. Further analyses were conducted on the DESI EFB1 and DES-G EFB2 samples, which were pretreated at the optimal pretreatment conditions of DES-I and DES-G to compare and determine the efficiency of these pretreatments.

\section{Performance of Choline Chloride-Imidazole (DES-I) and Choline Chloride- Glycerol (DES-G) Pretreated Empty Fruit Bunches (EFB) at Optimal Pretreatment Conditions}

Enzymatic hydrolysis of the DES-I EFB1 and DES-G EFB2 samples

Figure 4 illustrates the performance of the $1 \%$ enzymatic hydrolysis of the DES-I EFB1 and DES-G EFB2 samples using Cellic CTec2 and Cellic HTec2 enzymes. The DES-I EFB1, pretreated using DES-I with a EFB to solvent ratio of 1:5, a temperature of $160{ }^{\circ} \mathrm{C}$, and a treatment time of $2 \mathrm{~h}$, was successfully hydrolyzed by the enzymes, and it yielded $10.26 \mathrm{~g} / \mathrm{L} \pm 0.01 \mathrm{~g} / \mathrm{L}$ of glucose and $4.50 \mathrm{~g} / \mathrm{L} \pm 0.04 \mathrm{~g} / \mathrm{L}$ of xylose after a total of $72 \mathrm{~h}$ of hydrolysis (as shown in Fig. 4a). These were equivalent to the glucan and xylan conversions of $93 \%$ and $68.7 \%$, respectively. The hydrolysis profile also showed that after $48 \mathrm{~h}$ of hydrolysis, the conversion of glucan in the DES-I EFB1 sample already reached $89 \%$ and $67 \%$ for the glucan and xylan conversions. In contrast, the enzymatic hydrolysis of the DES-G EFB2 sample, pretreated using DES-G with a EFB to solvent ratio of 1:10, a temperature of $160{ }^{\circ} \mathrm{C}$ and a treatment time of $4 \mathrm{~h}$, produced lower sugar concentrations $(7.99 \mathrm{~g} / \mathrm{L} \pm 0.03 \mathrm{~g} / \mathrm{L}$ glucose and $3.59 \mathrm{~g} / \mathrm{L} \pm 0.04 \mathrm{~g} / \mathrm{L}$ xylose). These corresponded to $72.3 \%$ and $55.6 \%$ of the glucan and xylan conversions, respectively (as shown in Fig. 4b).

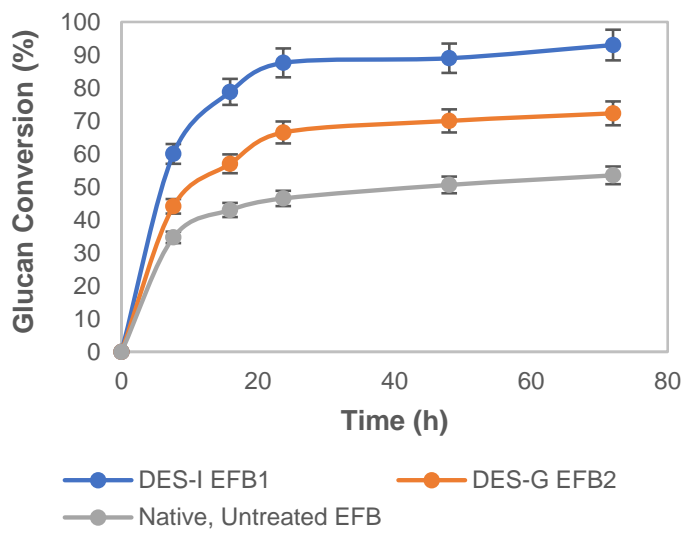

(a)

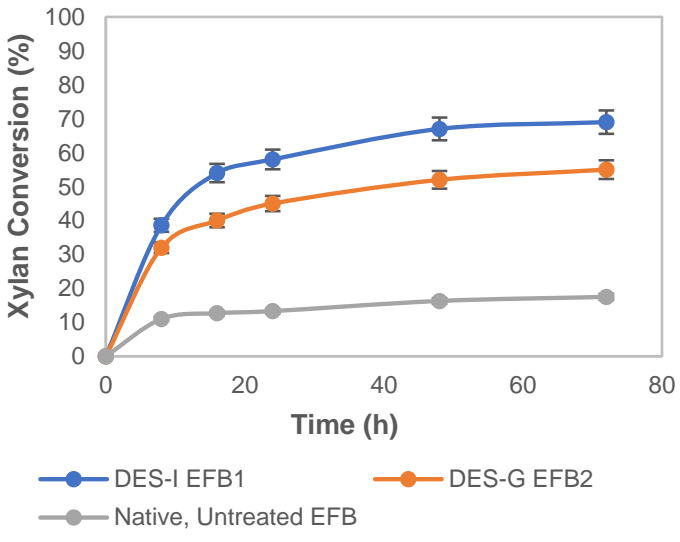

(b)

Fig. 4 Enzymatic hydrolysis of the DES-I EFB1 and DES-G EFB2 pretreated at a $1 \%$ glucan loading: (a) glucan conversion and (b) xylan conversion

Both the DES-I EFB1 and DES-G EFB2 samples showed an improvement in terms of carbohydrate hydrolysis when compared to the carbohydrate hydrolysis in the native EFB. The glucan hydrolysis increased by $73 \%$ and $35.1 \%$, respectively, for the DES-I 
EFB1 and DES-G EFB2 samples, exhibiting the potential of DES-I as a pretreatment solvent over DES-G. The improvement in the enzymatic hydrolysis was affected by the reduction in the lignin content and the low inhibitor content that resulted in an increase in pores sizes and surface area, which facilitated the carbohydrate digestion process.

$X$-ray diffraction $(X R D)$ analysis

The degree of crystallinity $(\mathrm{CrI})$ and structural changes in cellulose are the major factors that influence the effectiveness of the enzymatic saccharification of lignocellulosic biomass (Çetinkol et al. 2010). Figure 5 compares the x-ray diffractogram of the native EFB, DES-I EFB1, and DES-G EFB2, as well as the remaining unhydrolyzed solid residues, UH-DES-I EFB1 and UH-DES-G EFB2. In addition, commercial samples of pure cellulose (Avicel) and pure lignin were used as the control for comparison purposes.

The increase in CrI can be interpreted either as an increase in the crystalline phase or a decrease in the amorphous phase of the EFB. Figure 6 compares the CrI for all the samples. The native EFB sample had the lowest CrI (0.42), and the value increased to 0.6 and 0.53 for the DES-I EFB1 and DES-G EFB2 samples after DES pretreatment, respectively. Both pretreated EFB samples demonstrated that the DES pretreatment successfully removed the amorphous components, lignin, and hemicelluloses, which resulted in a higher crystallinity in the sample. The reason behind that could be that the strong hydrogen bond interactions in cellulose were weakened because of competing hydrogen bond formation between the chloride ions $\left(\mathrm{Cl}^{-}\right)$in DES and the $(-\mathrm{OH})$ groups in carbohydrates, consequently breaking the intramolecular hydrogen bond network. Furthermore, lignin removal by DES treatment would have exposed cellulose on the surface of the DES-treated EFB (Kwon et al., 2020). Kim et al. (2003) reported that enzyme saccharification responds positively with an increase in the CrI value.

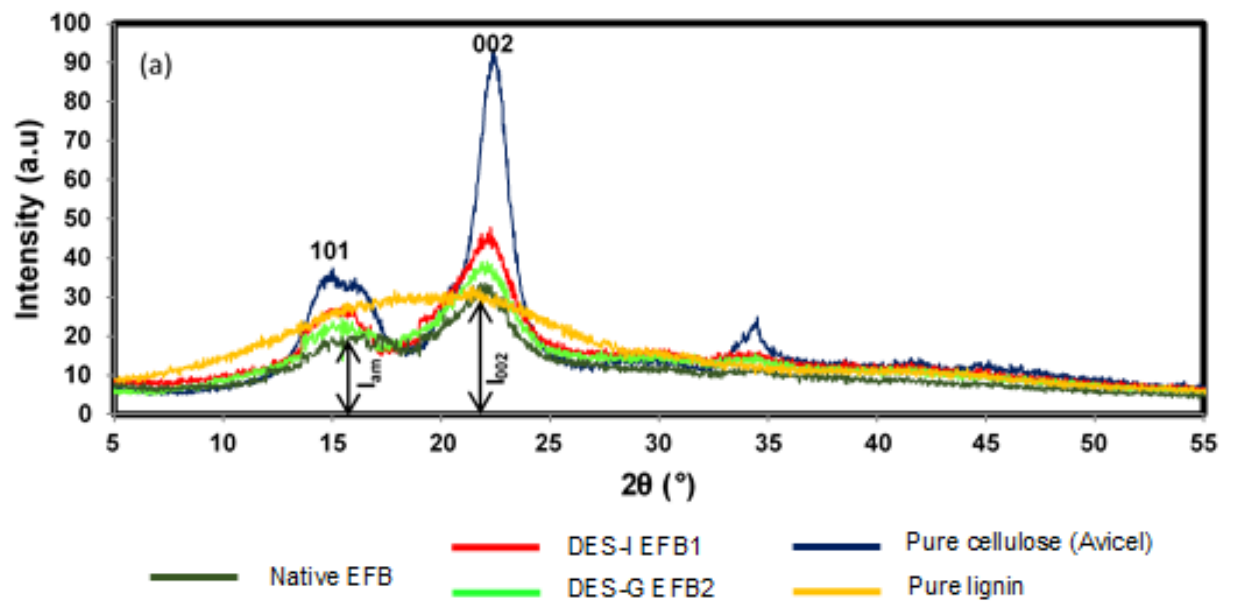

(a) 


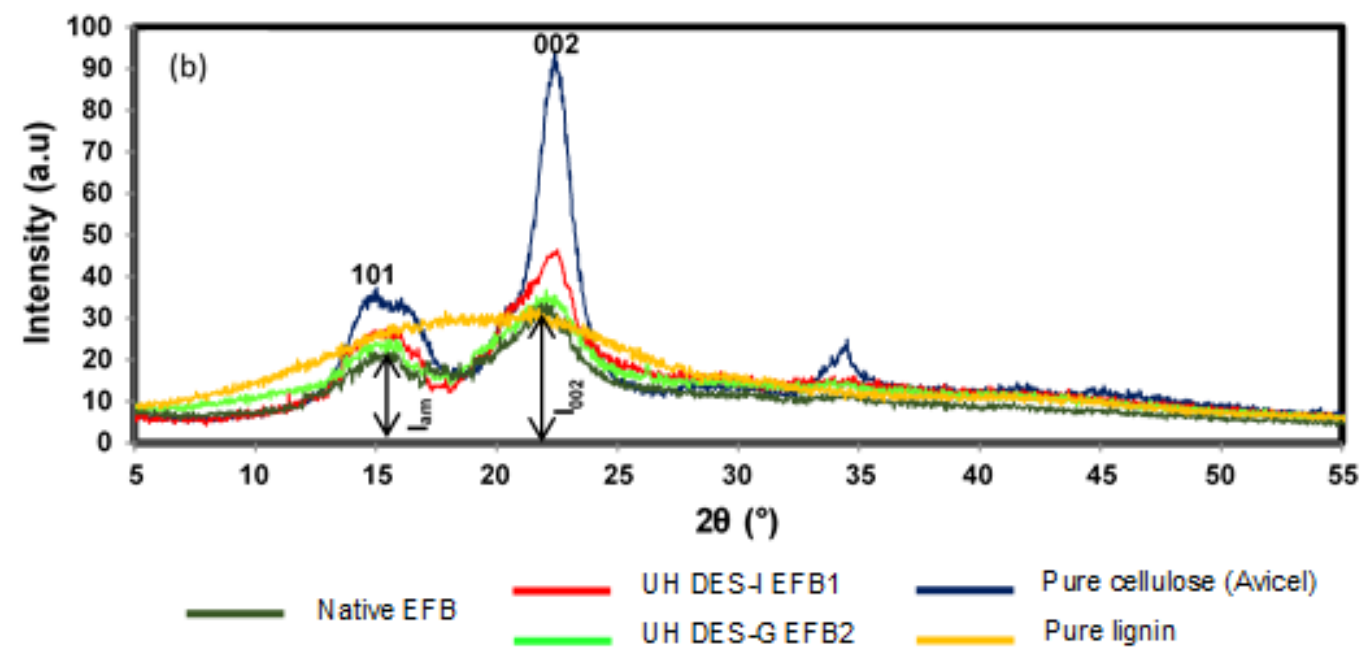

(b)

Fig. 5. X-ray diffractogram of the (a) native EFB, DES-I EFB1, DES-G EFB2, pure cellulose, and pure lignin; and (b) native EFB, UH-DES-I EFB1, UH-DES-G EFB2, pure cellulose, and pure lignin.

During enzymatic hydrolysis, more chemical linkages in the pretreated EFB were hydrolyzed, which degraded the pretreated EFB samples. This led to highly crystalline samples in the unhydrolyzed solid residues of UH DES-I EFB1 and UH DES-G EFB2 with $\mathrm{CrI}$ values of 0.74 and 0.62 , respectively. Commercial cellulose (Avicel) and lignin were used as the controls to show comparisons of the highest and lowest $\mathrm{CrI}$ in all the samples (as shown in Fig. 6).

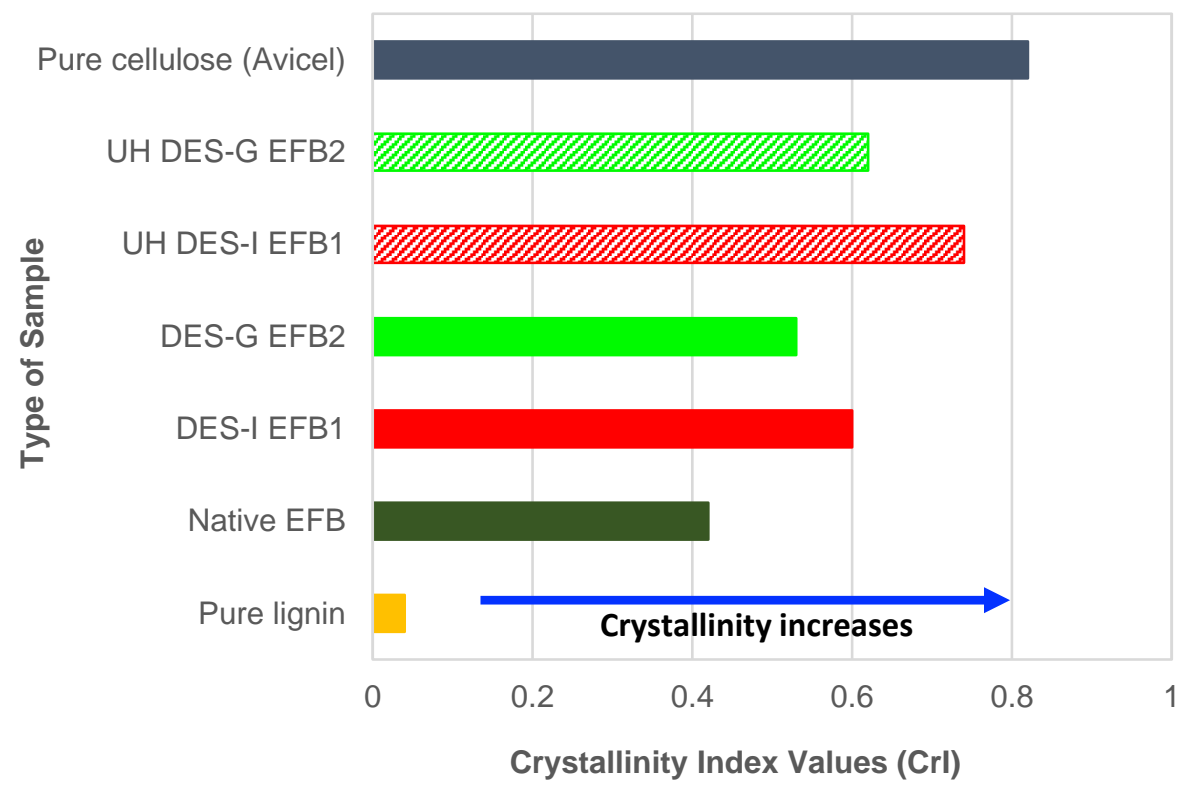

Fig. 6. Crystallinity index (Crl) value for native EFB, DES-I EFB1, DES-G EFB2, UH-DES-I EFB1, UH-DES-G EFB2, pure cellulose, and pure lignin 
Fourier transformation infra-red (FTIR) analysis

Figure 7 illustrates the FTIR spectra for the native EFB (1), DES-I EFB1 (2), DESG EFB2 (3), pure cellulose (4), pure lignin (5), UH DES-I EFB1 (6), and UH DES-G EFB2 (7) samples. There were seven peaks identified on the spectra ranging from 1020 to 3500 $\mathrm{cm}^{-1}$, labeled as Peak A to Peak G, that can be used to describe the intensity of the functional groups in all samples. Table 1 shows the characterization of the signal assignment for these seven peaks from the respective samples, as either a strong $(+)$, decreased (-), or diminished (NI) intensity of the related functional group. Notably, the varying intensity of the peak from DES-I EFB1 (2), DES-G EFB2 (3), UH DES-I EFB1 (6), and UH DES-G EFB2 (7) were primarily decreased or diminished in comparison to the peak intensity for native EFB (1) and pure lignin (5), signifying the effect of the DESI and DES-G pretreatments. This was particularly obvious for the DES-I EFB1 (2) and UH DES-I EFB1 (6) samples when the peak intensity resembled the peak intensity of pure cellulose (4), which indicated the efficiency of the DES-I pretreatment in removing hemicelluloses and lignin (as shown in Table 1).

Table 2 compares the lateral order index (LOI), total crystallinity index (TCI), and hydrogen-bond intensity (HBI) from the FTIR spectra for the native EFB (1), DES-I EFB1 (2), DES-G EFB2 (3), pure cellulose (4), pure lignin (5), UH DES-I EFB1 (6), and UH DES-G EFB2 (7) samples. The TCI is proportional to the degree of crystallinity in cellulose, and the LOI is correlated to the overall degree of order in cellulose. In addition, the HBI is related to the crystallinity system and degree of intermolecular regularity. 
Table 1. Characterization of the Signal Assignment for Peaks from Empty Fruit Bunch Samples and Controls

\begin{tabular}{|c|c|c|c|c|c|c|c|c|c|c|}
\hline \multirow[b]{2}{*}{$\begin{array}{l}\text { Peak } \\
\#\end{array}$} & \multirow[b]{2}{*}{$\begin{array}{l}\text { Peak } \\
\left(\mathrm{cm}^{-1}\right)\end{array}$} & \multirow[b]{2}{*}{ Signal Assignment } & \multicolumn{7}{|c|}{$\begin{array}{c}\text { Intensity Strength } \\
\text { Strong }=(+) \text {, Decreased }=(-) \text {, Diminished }=(\mathrm{NI})\end{array}$} & \multirow[b]{2}{*}{ Ref. } \\
\hline & & & $\begin{array}{l}\text { Native } \\
\text { EFB (1) }\end{array}$ & $\begin{array}{l}\text { DES-I } \\
\text { EFB1 } \\
\text { (2) }\end{array}$ & $\begin{array}{l}\text { DES-G } \\
\text { EFB2 } \\
\text { (3) }\end{array}$ & $\begin{array}{l}\text { UH } \\
\text { DES-I } \\
\text { EFB1 } \\
(6) \\
\end{array}$ & $\begin{array}{c}\text { UH } \\
\text { DES-G } \\
\text { EFB2 } \\
(7) \\
\end{array}$ & $\begin{array}{l}\text { Pure } \\
\text { cellulose } \\
(4)\end{array}$ & $\begin{array}{c}\text { Pure } \\
\text { lignin } \\
\text { (5) }\end{array}$ & \\
\hline A & $\begin{array}{l}3200 \text { to } \\
3500\end{array}$ & $\begin{array}{l}\text { O-H stretching in aromatic and aliphatic } \\
\text { groups of cellulose, hemicellulose, and } \\
\text { aromatic lignin }\end{array}$ & + & - & - & - & - & - & + & $\begin{array}{l}\text { Agrawal et } \\
\text { al. } 2017\end{array}$ \\
\hline B & $\begin{array}{l}2800 \text { to } \\
2940\end{array}$ & $\mathrm{C}-\mathrm{H}$ vibrations in $\mathrm{CH}_{3}$ and $\mathrm{CH}_{2}$ groups & + & - & - & - & - & - & + & $\begin{array}{l}\text { Agrawal et } \\
\text { al. } 2017\end{array}$ \\
\hline C & $\begin{array}{l}1718 \text { to } \\
1734\end{array}$ & $\begin{array}{c}\mathrm{C}=\mathrm{O} \text { stretching in hemicelluloses (ester } \\
\text { group) }\end{array}$ & + & $\mathrm{NI}$ & - & - & - & $\mathrm{NI}$ & + & $\begin{array}{l}\text { Sim et al. } \\
2012 ; \\
\text { Kurian et } \\
\text { al. } 2015\end{array}$ \\
\hline $\mathrm{D}$ & $\begin{array}{l}1622 \text { to } \\
1648\end{array}$ & $\mathrm{C}=\mathrm{O}$ stretching in lignin (ester group) & + & - & + & - & - & - & + & $\begin{array}{l}\text { Sim et al. } \\
2012 ; \\
\text { Kurian et } \\
\text { al. } 2015\end{array}$ \\
\hline $\mathrm{E}$ & $\begin{array}{l}1450 \text { to } \\
1550\end{array}$ & $\begin{array}{c}\text { Aliphatic and aromatic ring skeleton } \\
\text { vibration in lignin }\end{array}$ & + & $\mathrm{NI}$ & - & $\mathrm{NI}$ & - & $\mathrm{NI}$ & + & $\begin{array}{l}\text { Sim et al. } \\
2012 \\
\text { Li et al. } \\
2018\end{array}$ \\
\hline $\mathrm{F}$ & $\begin{array}{l}1140 \text { to } \\
1160\end{array}$ & $\begin{array}{l}\text { 1. C-O-C asymmetry ring vibrational } \\
\text { stretching in }(b-1,4) \text {-glycosidic bond } \\
\text { in cellulose and hemicellulose; } \\
\text { 2. C-H stretching vibration of syringyl } \\
\text { units/coumaric acid ester in lignin }\end{array}$ & $+^{1,2}$ & $+^{1}$ & $+^{1,2}$ & $+^{1}$ & $++^{1,2}$ & $++^{1}$ & $+^{2}$ & $\begin{array}{l}\text { Musule et } \\
\text { al. 2016; } \\
\text { Sim et al. } \\
\text { 2012; } \\
\text { Li et al. } \\
2018\end{array}$ \\
\hline $\mathrm{G}$ & $\begin{array}{c}1020 \text { to } \\
1040\end{array}$ & $\begin{array}{l}\text { 1. } \mathrm{C}-\mathrm{H} \text { bending vibration of guaiacyl } \\
\text { units; } \\
\text { 2. } \mathrm{C}-\mathrm{O}, \mathrm{C}-\mathrm{C}, \mathrm{C}=\mathrm{C}, \mathrm{C}-\mathrm{C}-\mathrm{O} \text { and } \mathrm{C}-\mathrm{OH} \\
\text { stretching vibrations of cellulose, } \\
\text { hemicellulose and lignin }\end{array}$ & + & - & + & - & - & - & + & $\begin{array}{l}\text { Li et al. } \\
2018 \text {; } \\
\text { Sim et al. } \\
2012\end{array}$ \\
\hline
\end{tabular}


Table 2. Crystallinity Indices Ratio from the FTIR Spectra

\begin{tabular}{|c|c|c|c|c|c|c|c|}
\hline $\begin{array}{c}\text { Crystallinity } \\
\text { Indices }\end{array}$ & $\begin{array}{c}\text { Lignin } \\
\text { (Control } \\
- \text { Low) }\end{array}$ & $\begin{array}{c}\text { Native } \\
\text { EFB }\end{array}$ & $\begin{array}{c}\text { DES-I } \\
\text { EFB 1 }\end{array}$ & $\begin{array}{c}\text { DES-G } \\
\text { EFB2 }\end{array}$ & $\begin{array}{c}\text { UH DES-I } \\
\text { EFB1 }\end{array}$ & $\begin{array}{c}\text { UH DES- } \\
\text { G EFB2 }\end{array}$ & $\begin{array}{c}\text { Cellulose- } \\
\text { Avicel } \\
\text { (Control - } \\
\text { High) }\end{array}$ \\
\hline LOI & 0.55 & 0.72 & 0.96 & 0.85 & 1.01 & 0.89 & 1.13 \\
\hline $\mathrm{TCl}$ & 0.61 & 0.85 & 1.17 & 0.99 & 1.25 & 1.18 & 1.29 \\
\hline $\mathrm{HBI}$ & 0.35 & 0.69 & 1.47 & 1.34 & 1.58 & 1.46 & 1.69 \\
\hline
\end{tabular}

The LOI, TCI, and HBI values in the samples increased after the DES-I and DES$\mathrm{G}$ pretreatments, and they continued to increase after the enzymatic hydrolysis, which implied that the samples were more crystalline in structure. This was mostly contributed by the cellulose remaining in the DES-I EFB1 (2), DES-G EFB2 (3), UH DES-I EFB1 (6), and UH DES-G EFB2 (7) samples after the removal of the fragmented amorphous structure, composed of hemicelluloses and lignin, during the DES pretreatment process (Kim et al. 2003; Lee et al. 2014). Both the DES-I EFB1 and unhydrolyzed UH DES-I EFB1 samples showed greater LOI, TCI, and HBI values compared to the DES-G EFB2 and UH DES-G EFB2 samples. These results might indicate that the removal of a considerable amount of the amorphous portion of the lignin and hemicelluloses during the DES-I pretreatment caused both the DES-I EFB1 and UH DES-I EFB1 samples to have the highest crystallinity degree as well as highly ordered cellulose structure, which leads to a higher hydrogen bond intensity between the neighboring hydrogens in the cellulose chain (Polleto et al. 2012). 

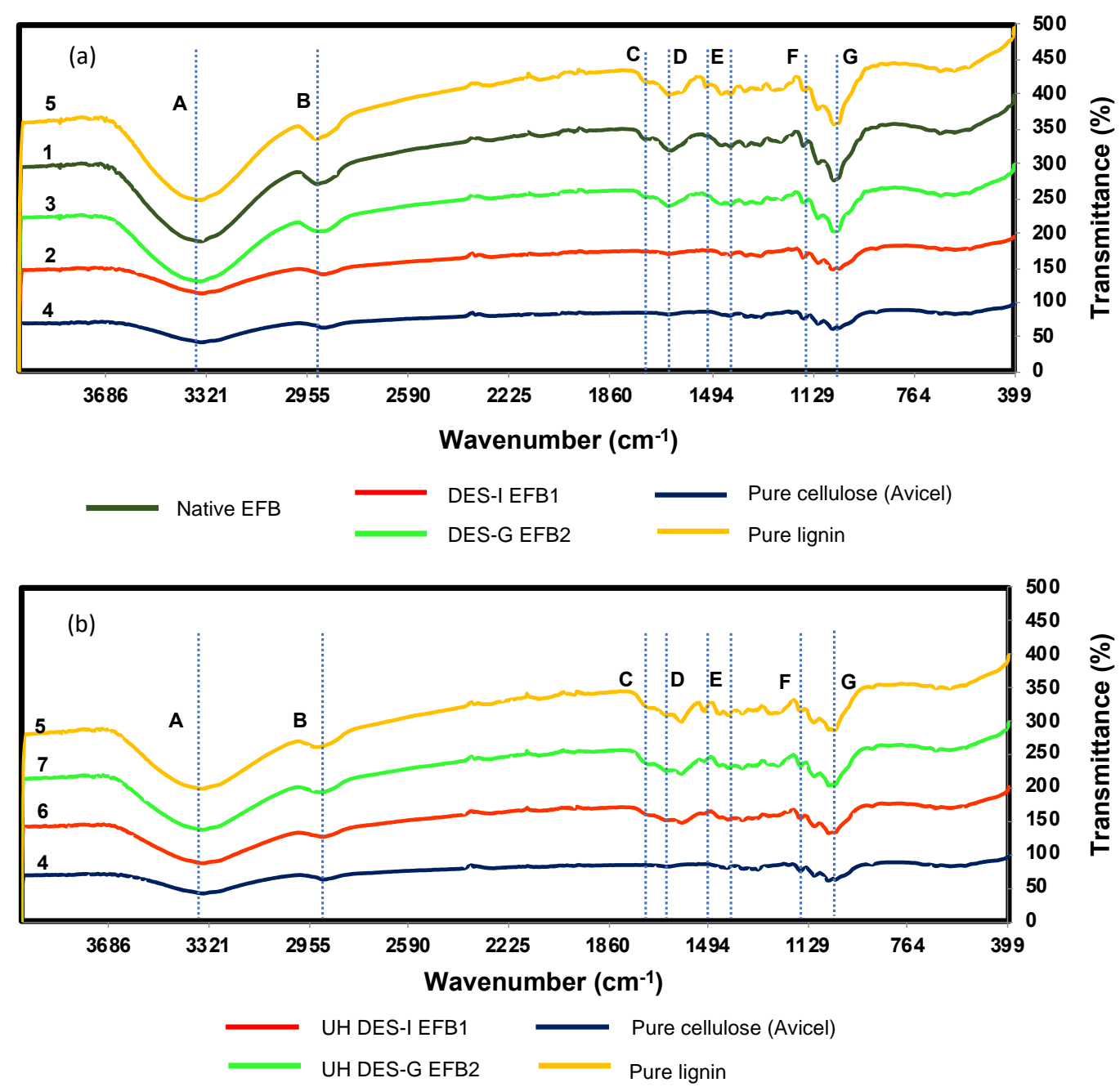

Fig. 7. FTIR spectra for the samples of the (a) native EFB, DES-I EFB1, DES-G EFB2, pure cellulose, and pure lignin, and (b) native EFB, UH-DES-I EFB1, UH-DES-G EFB2, pure cellulose, and pure lignin.

\section{Morphological properties of the samples using variable pressure scanning electron microscopy (VPSEM)}

Figure 8 shows the exterior surface morphology of native EFB, DES-I EFB1, DESG EFB2, UH DES-I EFB1, and UH DES-G EFB2 using VPSEM. The surface of the native untreated EFB (as shown in Fig. 8a) shows that most of the cuticle and silica layers were broken during the milling process, and the surface was contaminated by the broken cuticle debris due to the milling effect. A clear structure of silica bodies (SB) was observed on the native EFB fiber surface. 


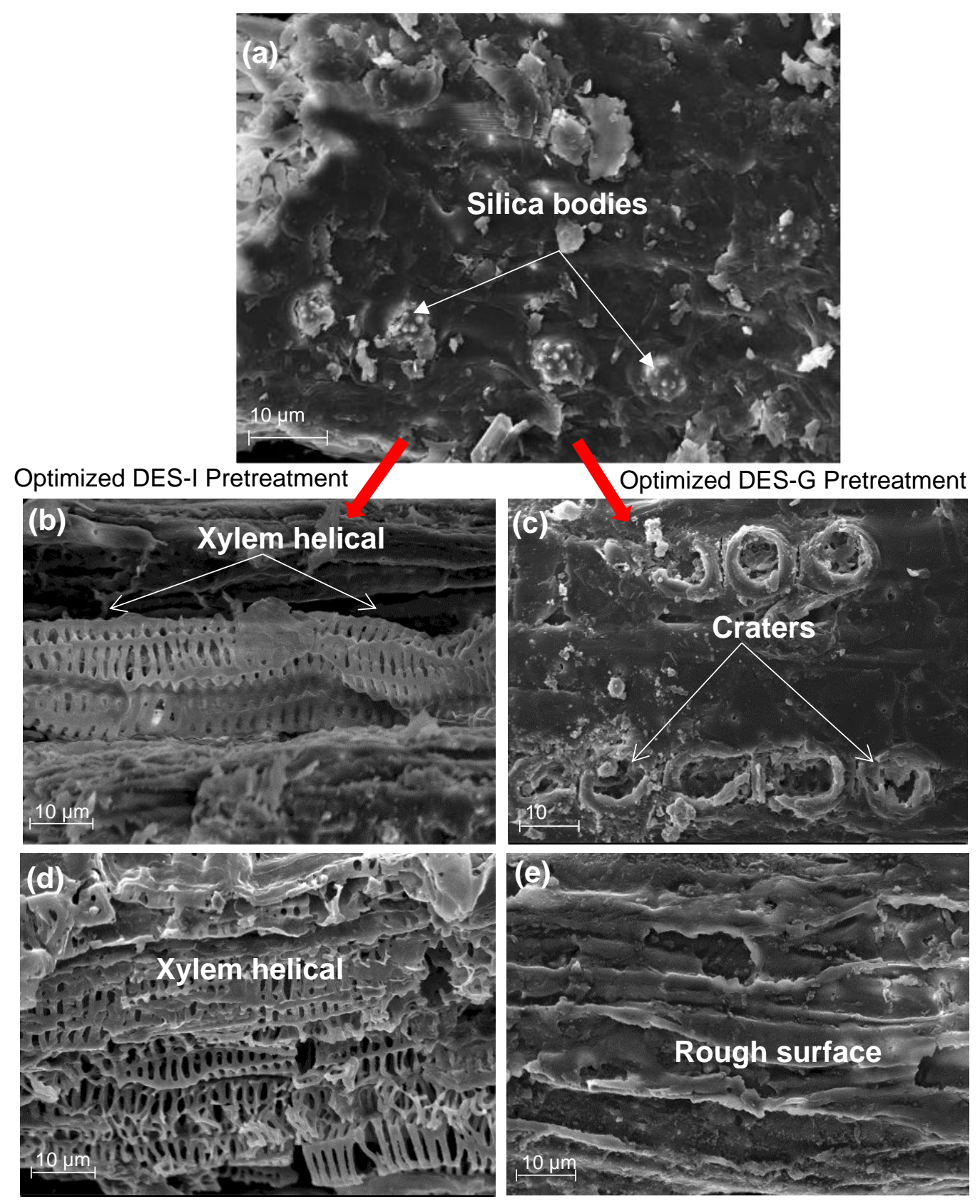

Fig. 8. Surface morphology via VPSEM of the (a) native EFB, (b) DES-I EFB1, (d) UH DES-I EFB1, (c) DES-G EFB2, and (e) UH DES-G EFB2 samples

The DES-I EFB1 sample showed the removal of a considerable amount of broken cuticle debris and silica bodies, which clearly exposed the helical coiled cellulosic microfibrils that reinforce the tracheary elements in plant xylem (as shown in Fig. 8b) (Gray 2015). The presence of cellulosic xylem helical structure became more obvious after the UH DES-I EFB1 sample underwent enzymatic hydrolysis (as shown in Fig. 8(d). The cellulose fiber structure was clearly exposed to the surface, which indicated the complete destruction and removal of the cuticle and silica layers (Bonnett 1972).

Figure 8c shows the visual observation of the DES-G EFB2 sample with some cuticle debris and craters. However, none of the cellulosic xylem helical structures were 
present in the DES-G EFB2 sample, showing the inefficiency of the DES-G pretreatment in deconstructing the microstructure of the EFB. The SEM observation of the surface of the UH DES-G EFB2 sample (as shown in Fig. 8e) only showed the rough surface structure, even after undergoing enzymatic hydrolysis, and it was not the same as the surface of the UH DES-I EFB1 sample. The optimal DES-I pretreatment removed greater amounts of lignin compared to the optimal DES-G pretreatment. The epidermal layer of the DES-I EFB1 was torn, peeled, and considerably ruptured. Most of the craters of the silica body initially found on the surface of the surface of the native EFB were destroyed. The delignification not only removed the relatively hydrophobic lignin but also the cuticle debris and silica on the EFB surface, causing the defibrillated inner microfibrils to become considerably exposed.

\section{CONCLUSIONS}

1. Both the DES-I and DES-G deep eutectic solvent pretreatments were shown to be effective in reducing the lignin content and cellulose crystallinity, which enhanced the enzymatic digestibility of empty fruit bunch.

2. Even so, DES-I demonstrated a $92.4 \%$ and $68.7 \%$ glucan and xylan conversion rate, respectively, which was higher than the DES-G pretreatment glucan and xylan conversion rate $(72.3 \%$ and $55.6 \%$, respectively).

3. In addition, the DES-I pretreatment could be applied at a low loading ratio of EFB to DES (1:5) at a temperature of $160{ }^{\circ} \mathrm{C}$ for only $2 \mathrm{~h}$. However, the use of the DES-G pretreatment required a higher ratio of biomass to DES (1:10) loading at a temperature of $160{ }^{\circ} \mathrm{C}$ for $4 \mathrm{~h}$ to achieve similar results.

4. The optimum pretreatment conditions applied in this study for both DES-I and DES-G resulted in low inhibitors concentration in the resulting black liquor from the DES pretreatment.

5. The Fourier transform infrared (FTIR) and X-ray diffraction (XRD) analyses also showed verification of hemicellulose degradation after the DES pretreatment.

6. The morphological analyses of the DES-I pretreated EFB indicated that the removal of a considerable amount of cuticle and silica bodies made it highly exposed to enzymatic hydrolysis.

7. Thus, the DES pretreatment seems to be a promising method as a bioconversion processes for empty fruit bunches.

\section{ACKNOWLEDGMENTS}

The authors would like to thank the Universiti Kebangsaan Malaysia (UKM) for the financial support under University Research Grant (GUP-2019-016) and Center for Research and Instrumentation (CRIM), UKM for providing the scanning electron microscopy (SEM) and X-ray diffraction sample analyses. This research work was also funded by the Yayasan Sime Darby Excellent Scholarship. The authors also thank the academic staff of the CESPRO and Biorefinery Laboratory and also the laboratory 
members who supported this research study.

\section{REFERENCES CITED}

Abdul, P. M., Jahim, J. M., Harun, S., Markom, M., Lutpi, N. A., Hassan, O., Balan, V., Dale, B. E., and Nor, M. T. M. (2016). "Effects of changes in chemical and structural characteristic of ammonia fibre expansion (AFEX) pretreated oil palm empty fruit bunch fibre on enzymatic saccharification and fermentability for biohydrogen," Bioresource Technology 211, 200-208. DOI: 10.1016/j.biortech.2016.02.135

Agrawal, R., Satlewal, A., Kapoor, M., Mondal, S., and Basu, B. (2017). "Investigating the enzyme-lignin binding with surfactants for improved saccharification of pilot scale pretreated wheat straw," Bioresource Technology 224, 411-418. DOI: 10.1016/j.biortech.2016.11.026

Aini, A. P., Lee, H. W., Sitompul, J. P., and Rasrendra, C. B. (2018). "Production of lactic acid from empty fruit bunch of palm oil using catalyst of barium hydroxide," MATEC Web of Conferences 156, 1-6. DOI: 10.1051/matecconf/201815606004

Arumugam, A., Malolan, V. V., and Ponnusami, V. (2020). "Contemporary pretreatment strategies for bioethanol production from corncobs: A comprehensive review," Waste and Biomass Valorization 12(4), 577-612. DOI: 10.1007/s12649-020-00983-w

Banerjee, N., Bhatnagar, R., and Viswanathan, L. (1981). "Inhibition of glycolysis by furfural in Saccharomyces cerevisiae," European Journal of Applied Microbiology and Biotechnology 11, 226-228. DOI: 10.1007/BF00505872

Brandt, A., Gräsvik, J., Halletta, J. P., and Welton, T. (2013). "Deconstruction of lignocellulosic biomass with ionic liquids," Green Chemistry 15(3), 550-583. DOI: 10.1039/C2GC36364J

Bukhari, N. A., Jahim, J. M., Loh, S. K., Bakar, N. A., and Luthfi, A. A. I. (2019). "Response surface optimisation of enzymatically hydrolysed and dilute acid pretreated oil palm trunk bagasse for succinic acid production," BioResources 14(1), 1679-1693. DOI: 10.15376/biores.14.1.1679-1693

Cara, C., Romero, I., Oliva, J. M., Sáez, F., and Castro, E. (2007). "Liquid hot water pretreatment of olive tree pruning residues," Applied Biochemistry and Biotechnology 136-140, 379-394. DOI: 10.1007/s12010-007-9066-y

Çetinkol, Ö. P., Dibble, D. C., Cheng, G., Kent, M. S., Knierim, B., Auer, M., Wemmer, D. E., Pelton, J. G., Melnichenko, Y. B., Ralph, J., et al. (2010). "Understanding the impact of ionic liquid pretreatment on eucalyptus," Biofuels 1(1), 33-46. DOI: 10.4155/bfs.09.5

Chen, Y., Zhang, L., Yu, J., Lu, Y., Jiang, B., Fan, Y., and Wang, Z. (2019). "High-purity lignin isolated from poplar wood meal through dissolving treatment with deep eutectic solvents," Royal Society Open Science 6(1), 1-11. DOI: 10.1098/rsos.181757

Degam, G. (2017). Deep Eutectic Solvents Synthesis, Characterization and Applications in Pretreatment of Lignocellulosic Biomass, Ph.D. Dissertations, South Dakota State University, Brookings, South Dakota.

Delgenes, J. P., Moletta, R., and Navarro, J. M. (1996). "Effects of lignocellulose degradation products on ethanol fermentations of glucose and xylose by Saccharomyces cerevisiae, Zymomonas mobilis, Pichia stipitis, and Candida shehatae," Enzyme and Microbial Technology 19(3), 220-225. DOI: 10.1016/01410229(95)00237-5 
Gray, D. G. (2015). "Isolation and handedness of helical coiled cellulosic thickenings from plant petiole tracheary elements," Cellulose 21, 3181-3191. DOI: 10.1007/s10570-014-0382-4

Hassan, E. S. R. E., and Mutelet, F. (2017). "Use of ionic liquids for the treatment of biomass materials and biofuel production in carbohydrate," in: Carbohydrate, M. Çalışkan, H. Kavaklı, and G. C. Öz (ed.), IntechOpen, London, UK.

Horváth, I. T., Malacria, M., Kadish, K. M., and Guilard, R. (2017). Advanced Green Chemistry: Part 1: Greener Organic Reactions and Processes, World Scientific Publishing Co., Singapore.

Jeong, T. S., Choi, C. H., Lee, J. Y., Oh, K. K. (2012). "Behaviors of glucose decomposition during acid-catalyzed hydrothermal hydrolysis of pretreated Gelidium amansii," Bioresource Technology 116, 435-440. DOI: 10.1016/j.biortech.2012.03.104

Jönsson, L. J., Alriksson, B., and Nilvebrant, N. O. (2013). "Bioconversion of lignocellulose: Inhibitors and detoxification," Biotechnology for Biofuels 6(1), 1-10. DOI: $10.1186 / 1754-6834-6-16$

Kalhor, P., and Ghandi, K. (2019). "Deep eutectic solvents for pretreatment, extraction, and catalysis of biomass and food waste," Molecules 24(22), 1-37. DOI: 10.3390/molecules 24224012

Kim, T. H., Kim, J. S., Sunwoo, C., and Lee, Y. Y. (2003). "Pretreatment of corn stover by aqueous ammonia," Bioresource Technology 90(1), 39-47. DOI: 10.1016/S09608524(03)00097-X

Koshijima, T., and Watanabe, T. (2013). Association Between Lignin and Carbohydrates in Wood and Other Plant Tissues, Springer-Verlag, Berlin, Heidelberg.

Kurian, J. K., Gariépy, Y., Orsat, V., and Raghavan, V. (2015). "Microwave-assisted lime treatment and recovery of lignin from hydrothermally treated sweet sorghum bagasse," Biofuels 6(5-6), 1-15. DOI: 10.1080/17597269.2015.1110775

Kwon, G., Yang, B., Park, C., Bandi, R., Lee, E., Park, J., Han, S., Kim, N., and Lee, S. (2020). "Treatment effects of choline chloride-based deep eutectic solvent on the chemical composition of red pine (Pinus densiflora)," BioResources 15(3), 64576470. DOI: 10.15376/biores.15.3.6457-6470

Lee, H. V, Hamid, S. B. A., and Zain, S. K. (2014). "Conversion of lignocellulosic biomass to nanocellulose: Structure and chemical process," The Scientific World Journal 2014, 1-20. DOI: 10.1155/2014/631013

Lehmann, C., Bocola, M., Streit, W. R., Martinez, R., and Schwaneberg, U. (2014). "Ionic liquid and deep eutectic solvent-activated CelA2 variants generated by directed evolution," Applied Microbiology and Biotechnology 98(12), 5775-5785. DOI: 10.1007/s00253-014-5771-y

Li, T., Lyu, G., Saeed, H. A. M., Liu, Y., Wu, Y., Yang, G., and Lucia, L. A. (2018). "Analytical pyrolysis characteristics of enzymatic/mild acidolysis lignin (EMAL)," BioResources 13(2), 4484-4496. DOI: 10.15376/biores.13.2.4484-4496

Linh, T. N., Fujita, H., and Sakoda, A. (2017). "Release kinetics of esterified p-coumaric acid and ferulic acid from rice straw in mild alkaline solution," Bioresource Technology 232, 192-203. DOI: 10.1016/j.biortech.2017.02.009

Luthfi, A. A. I., Jahim, J. M., Harun, S., Tan, J. P., Manaf, S. F. A., and Shah, S. S. M. (2018). "Kinetics of the bioproduction of succinic acid by Actinobacillus succinogenes from oil palm lignocellulosic hydrolysate in a bioreactor," BioResources 13(4), 8279-8294. DOI: 10.15376/biores.13.4.8279-8294 
Majová, V., Horanová, S., Škulcová, A., Šima, J., and Jablonský, M. (2017). “Deep eutectic solvent delignification: impact of initial lignin," BioResources 12(4), 73017310. DOI: 10.15376/biores.12.4.7301-7310

Mahmod, S. S., Jahim, J. M., and Abdul, P. M. (2017). "Pretreatment conditions of palm oil mill effluent (POME) for thermophilic biohydrogen production by mixed culture," International Journal of Hydrogen Energy 42(45), 27512-27522. DOI: 10.1016/j.ijhydene.2017.07.178

MBIC. (2016). Malaysia Biomass Industries Review 2015/2016, Malaysia Biomass Industries Confederation, Putrajaya, Malaysia.

Menegazzo, F., Ghedini, E., and Signoretto, M. (2018). "5-hydroxymethylfurfural (HMF) production from real biomasses," Molecules 23(9), 2201-2219. DOI: 10.3390/molecules23092201

Morais, A. R. C., Pinto, J. V., Nunes, D., Roseiro, L. B., Oliveira, M. C., Fortunato, E., and Lukasik, R. M. (2015). "Imidazole: Prospect solvent for lignocellulosic biomass fractionation and delignification," ACS Sustainable Chemistry \& Engineering 4(3), 1643-1652. DOI: 10.1021/acssuschemeng.5b01600

Musule, R., Alarcón-Gutiérrez, E., Houbron, E. P., Bárcenas-Pazos, G. M., PinedaLópez, M. d. R., Domínguez, Z., and Sánchez-Velásquez, L. R. (2016). “Chemical composition of lignocellulosic biomass in the wood of Abies religiosa across an altitudinal gradient," Journal of Wood Science 62, 537-547. DOI: 10.1007/s10086016-1585-0

Nor, N. A. M., Mustapha, W. A. W., and Hassan, O. (2016). "Deep eutectic solvent (DES) as a pretreatment for oil palm empty fruit bunch (OPEFB) in sugar production," Procedia Chemistry 18, 147-154. DOI: 10.1016/j.proche.2016.01.023

Oh, S. Y., Dong, I. Y., Shin, Y., Hwan, C. K., Hak, Y. K., Yong, S. C., Won, H. P., and Ji, H. Y. (2005). "Crystalline structure analysis of cellulose treated with sodium hydroxide and carbon dioxide by means of X-ray diffraction and FTIR spectroscopy," Carbohydrate Research 340(15), 2376-2391. DOI: 10.1016/j.carres.2005.08.007

Prado, R., Erdocia, X., Serrano, L., and Labidi, J. (2012). "Lignin purification with green solvents," Cellulose Chemistry and Technology 46(3-4), 221-225.

Procentese, A., Johnson, E., Orr, V., Campanile, A. G., Wood, J. A., Marzocchella, A., and Rehmann, L. (2015). "Deep eutectic solvent pretreatment and subsequent saccharification of corncob," Bioresource Technology 192, 31-36. DOI: 10.1016/j.biortech.2015.05.053

Procentese, A., Raganati, F., Olivieri, G., Russo, M. E., Rehmann, L., and Marzocchella, A. (2017). "Low-energy biomass pretreatment with deep eutectic solvents for biobutanol production," Bioresource Technology 243, 464-473. DOI: 10.1016/j.biortech.2017.06.143

Quek, J. D., Lee, K. M., Lim, S., Tey, W. Y., Kang, H-S., and Quen, L. K. (2020). "Delignification of oil palm empty fruit bunch via ultrasound-assisted deep eutectic solvent pretreatment," in: Proceedings of the International Conference on Sustainable Energy and Green Technology, 11-14 December, Bangkok, Thailand, pp. 1-7.

Rahim, A. H. A., Yunus, N. M., Hamzah, W. S. W., Sarwono, A., and Muhammad, N. (2021). "Low-viscosity ether-functionalized ionic liquids as solvents for the enhancement of lignocellulosic biomass dissolution," Processes 9(2), 1-16. DOI: $10.3390 /$ pr9020261

Roy, R., Rahman, M. S., and Raynie, D. E. (2020). "Recent advances of greener pretreatment technologies of lignocellulose," Current Research in Green and 
Sustainable Chemistry 3, 1-17. DOI: 10.1016/j.crgsc.2020.100035

Safri, N. A., Jalil, R., and Kalil, M. S. (2017). "Fermentable sugars from agrowastes using cellulase enzymes from local white rot fungi Pycnoporus sanguineus," Jurnal Kejuruteraan 29(2), 105-111. DOI: 10.17576/jkukm-2017-29(2)-06

Sai, Y. W., and Lee, K. M. (2019). "Enhanced cellulase accessibility using acid-based deep eutectic solvent in pretreatment of empty fruit bunches," Cellulose 26, 9517 9528. DOI: $10.1007 / \mathrm{s} 10570-019-02770-\mathrm{w}$

Shah, S. S. M., Luthfi, A. A. I., Jahim, J. M., Harun, S., and Low, K. O. (2020). “An improvement in fermentability of acid-hydrolysed hemicellulose from kenaf stem for xylitol production," International Journal of Food Engineering 16(10), 1-10. DOI: doi.org/10.1515/ijfe-2019-0230

Sim, S. F., Mohamed, M., Lu, N. A. L. M. I., Sarman, N. S. P., and Samsudin, S. N. S. (2012). "Computer-assisted analysis of Fourier transform infrared (FTIR) spectra for characterization of various treated and untreated agriculture biomass," BioResources 7(4), 5367-5380. DOI: 10.15376/BIORES.7.4.5367-5380

Sluiter, A., Hames, B., Ruiz, R., Scarlata, C., Sluiter, J., Templeton, D., and Crocker, D. (2012). Determination of Structural Carbohydrates and Lignin in Biomass Determination of Structural Carbohydrates and Lignin in Biomass (NREL/TP-51042618), National Renewable Energy Laboratory, Golden, CO.

Tan, Y. T., Ngoh, G. C., and Chua, A. S. M. (2018). "Evaluation of fractionation and delignification efficiencies of deep eutectic solvents on oil palm empty fruit bunch," Industrial Crops and Products 123, 271-277. DOI: 10.1016/j.indcrop.2018.06.091

Thi, S., and Lee, K. M. (2019). "Comparison of deep eutectic solvents (DES) on pretreatment of oil palm empty fruit bunch (OPEFB): Cellulose digestibility, structural and morphology changes," Bioresource Technology 282, 525-529. DOI: 10.1016/j.biortech.2019.03.065

Tian, D., Guo, Y., Hu, J., Yang, G., Zhang, J., Luo, L., Xiao, Y., Deng, S., Deng, O., Zhou, W., et al. (2020). "Acidic deep eutectic solvents pretreatment for selective lignocellulosic biomass fractionation with enhanced cellulose reactivity," International Journal of Biological Macromolecules 142, 288-297. DOI: 10.1016/j.ijbiomac.2019.09.100

Wilkes, J. S. (2002). "A short history of ionic liquids - From molten salts to neoteric solvents," Green Chemistry 4(2), 73-80. DOI: 10.1039/b110838g

Xia, S., Baker, G. A., Li, H., Ravula, S., and Zhao, H. (2014). "Aqueous ionic liquids and deep eutectic solvents for cellulosic biomass pretreatment and saccharification," RSC Advances 4(21), 10586-10596. DOI: 10.1039/C3RA46149A

Zhang, Q. H., Vigier, K. D. O., Royer, S., and Jerome, F. (2012). "Deep eutectic solvents: syntheses, properties and applications," Chemical Society Reviews 41(21), 71087146. DOI: $10.1039 / \mathrm{C} 2 \mathrm{cs} 35178 \mathrm{a}$

Zhao, H., Zhang, C., and Crittle, T. D. (2013). "Choline-based deep eutectic solvents for enzymatic preparation of biodiesel from soybean oil," Journal of Molecular Catalysis B: Enzymatic 85-86, 243-247. DOI: 10.1016/j.molcatb.2012.09.003

Article submitted: May 27, 2021; Peer review completed: June 27, 2021; Revisions accepted: July 27, 2021; Published: July 29, 2021.

DOI: 10.15376/biores.16.3.6313-6341 